\title{
Colonic MUC2 mucin regulates the expression and antimicrobial activity of $\beta$-defensin 2
}

\author{
ER Cobo $^{1}$, V Kissoon-Singh ${ }^{1}$, F Moreau $^{1}$ and K Chadee ${ }^{1}$
}

In this study we identified mechanisms at the colonic mucosa by which MUC2 mucin regulated the production of $\beta$-defensin in a proinflammatory milieu but functionally protected susceptible bacteria from its antimicrobial effects. The regulator role of MUC2 on production of $\beta$-defensin 2 in combination with the proinflammatory cytokine interleukin-1 $\beta$ (IL-1ß) was confirmed using purified human colonic MUC2 mucin and colonic goblet cells short hairpin RNA (shRNA) silenced for MUC2. In vivo, Muc2 ${ }^{-I_{-}^{-}}$mice showed impaired $\beta$-defensin mRNA expression and peptide localization in the colon as compared with $\mathrm{Muc2}^{+/-}$and $\mathrm{Muc2}^{+/+}$littermates. Importantly, purified MUC2 mucin abrogated the antimicrobial activity of $\beta$-defensin 2 against nonpathogenic and enteropathogenic Escherichia coli. Sodium metaperiodate oxidation of MUC2 removed the capacity of MUC2 to stimulate $\beta$-defensin production and MUC2's inhibition of defensin antimicrobial activity. This study highlights that a defective MUC2 mucin barrier, typical in inflammatory bowel diseases, may lead to deficient stimulation of $\beta$-defensin 2 and an unbalanced microbiota that favor the growth of $\beta$-defensin-resistant microbes such as Clostridium difficile.

\section{INTRODUCTION}

The colonic mucosa is covered by gel-forming glycosylated MUC2 mucin secreted by goblet cells that is organized as an inner sterile layer firmly attached to the epithelium and an outer layer with an expanded volume and colonized by bacteria. ${ }^{1}$ Embedded in colonic mucin are host defensin peptides, a group of small molecules (12-50 amino acids) divided into subgroups on the basis of their amino-acid composition and structure. Cationic defensin peptides are classified as $\alpha$ or $\beta$ based on their size and intramolecular disulfide bond patterns between six cysteines. ${ }^{2}$ Defensins are of interest because they are effective in killing a broad spectrum of microbes, including Escherichia coli, ${ }^{3}$ and have immune modulatory functions including chemotaxis of dendritic and $\mathrm{T}$ cells. ${ }^{4}$ In the colon, human $\beta$-defensin 2 (hBD-2) secreted by epithelial cells are the main representative of the host defensin peptides and are modulated by inflammatory and bacterial stimuli. $^{5,6}$

The microbiota establishes a symbiotic and healthy relationship in the colonic lumen, ${ }^{7}$ although it is constantly exposed to mucin and antimicrobial peptides. Modulation between colonic MUC2 mucin and $\beta$-defensin and their influence on the microbiota is unknown, although their dysfunction contributes to the pathogenesis of inflammatory bowel diseases. In ulcerative colitis, expression of $\beta$-defensin mRNA is increased in epithelial cells ${ }^{8,9}$ and the adherent mucus gel is thin and even denuded in patches ${ }^{10,11}$ with lower goblet cells numbers. ${ }^{12}$ In Crohn's disease, the colonic mucin layers appear normal but glycosylation patterns and functional properties are altered $^{10,11}$ and $\beta$-defensin expression is diminished. ${ }^{8,9}$ Moreover, microbiota dysbiosis with decreased complexity of the microbial ecosystem is characteristic of both Crohn's disease and ulcerative colitis. ${ }^{13}$ These studies suggest that there is a fine balance in the colon between MUC2 mucin and antimicrobial peptides that function together to prevent colonization by pathogens and at the same time protect the indigenous microbiota. To gain insights into the innate host defense mechanisms at the surface of the colonic mucosa, we studied the interaction between MUC2 mucin and $\beta$-defensin 2 in association with commensal microbiota or disease. Here we show that MUC2 mucin plays a dual functional role in the colon to stimulate $\beta$-defensin production in the presence of the proinflammatory cytokine interleukin-1 $\beta$ (IL-1 $\beta$ ) and adenosine triphosphate (ATP) and at the same time protects

${ }^{1}$ Department of Microbiology, Immunology and Infectious Diseases, Gastrointestinal Research Group, Snyder Institute for Chronic Diseases, Faculty of Medicine, University of Calgary, Calgary, Alberta, Canada. Correspondence: K Chadee (kchadee@ucalgary.ca)

Received 8 July 2014; accepted 18 March 2015; published online 29 April 2015. doi:10.1038/mi.2015.27 
otherwise $\beta$-defensin susceptible enteropathogenic E. coli (EPEC) or nonpathogenic E. coli.

\section{RESULTS \\ MUC2 mucin in combination with proinflammatory IL-1ß stimulates hBD-2 in colonic epithelial cells}

The modulatory effect of MUC2 mucin on $\beta$-defensin production was determined in cultured colonic cells under conditions that represent proinflammatory or physiological states. Inflammatory conditions were represented by IL-1 $\beta$, a proinflammatory cytokine released by macrophages and dendritic cells associated with colitis, ${ }^{14}$ and extracellular ATP, a danger molecule either from stressed, injured, and necrotic intestinal cells ${ }^{15,16}$ or from bacteria. ${ }^{17}$ Physiological conditions were represented by sodium butyrate, a normal colonic probiotic product and primary fuel of colonocytes associated with prevention of colorectal diseases. ${ }^{18,19}$ These stimulatory conditions were assessed in human colonic epithelial adenocarcinoma HT-29 cells that express hBD-2 in response to inflammatory and bacterial stimuli ${ }^{5}$ and constitutively express low levels of MUC2 mRNA and secrete small amounts of mucin. $^{20,21}$

To determine whether MUC2 mucin can regulate hBD-2 expression and peptide production, cells were stimulated with purified secreted MUC2 mucin isolated from human colon adenocarcinoma LS 174T goblet cells (Supplementary Figure S1A-C online). The purified LS 174T MUC2 mucin showed no contaminating MUC5AC or MUC5B or other proteins (Supplementary Figure S1D,E). Purified MUC2 mucin alone (up to $40 \mu \mathrm{g} \mathrm{ml}^{-1}$ ) caused a modest increase in hBD-2 mRNA (Figure 1a) and a greater effect on hBD-2 peptide release in HT-29 cells (Figure 2a) but none of these differences were significant. However, from preliminary studies, we have established that stimulating HT-29 cells with graded dosages of IL- $1 \beta$ $\left(0-40 \mathrm{ng} \mathrm{ml}^{-1}\right),{ }^{5}$ butyrate $(0-40 \mathrm{~mm}),{ }^{22}$ and ATP $(0-10 \mathrm{~mm})^{17}$ alone for up to $16 \mathrm{~h}$ show that $20 \mathrm{ng} \mathrm{ml}^{-1}$ of IL- $1 \beta$ and $20 \mathrm{~mm}$ of butyrate induced modest hBD-2 mRNA expression ( $\sim 4$ - and 2.5-fold change, respectively), whereas ATP did not (data not shown). Based on these observations we then investigated whether simultaneous stimulation with these mediators plus exogenously added MUC2 mucin could influence hBD-2. Our results showed that simultaneous addition of MUC2 mucin $\left(\geq 10 \mu \mathrm{g} \mathrm{ml}^{-1}\right)$ and IL-1 $\beta\left(20 \mathrm{ng} \mathrm{ml}^{-1}\right)$ for $16 \mathrm{~h}$ induced significantly elevated hBD-2 mRNA expression (eightfold change; Figure 1b) and peptide release (Figure 2b). Similarly, ATP (7.5 mM) simultaneously cocultured with MUC2 mucin (with $0.7-3 \mu \mathrm{g} \mathrm{ml}^{-1}$ of MUC2) for $16 \mathrm{~h}$ increased hBD2 mRNA and peptide release (with $\geq 25 \mu \mathrm{g} \mathrm{ml}^{-1}$ of MUC2; Figures $1 \mathrm{c}$ and 2c). In contrast, cells incubated with the highest tested dose of butyrate $(20 \mathrm{mM})$ plus exogenously added MUC2 had no effect on hBD-2 (Figures 1d and 2d). The stimulatory effect on hBD-2 expression by IL-1 $\beta\left(20 \mathrm{ng} \mathrm{ml}^{-1}\right)$ or ATP $(7.5 \mathrm{mM})$ in combination with MUC2 (40 and $3 \mu \mathrm{g} \mathrm{ml}^{-1}$ for IL-1 $\beta$ and ATP, respectively) was completely inhibited by bisindolylmaleimide I, a highly selective, cell-permeable, and reversible protein kinase $\mathrm{C}(\mathrm{PKC})$ inhibitor (Figure 1e,f).
By confocal immunofluorescence, low intracellular localization of hBD-2 was homogenously seen in the cytoplasm of control HT-29 cells. However, cells treated with MUC2 mucin $\left(20 \mu \mathrm{g} \mathrm{ml}^{-1}\right)$ and either IL-1 $\left(20 \mathrm{ng} \mathrm{ml}^{-1}\right)$ or ATP $(7.5 \mu \mathrm{M})$, but not butyrate $(20 \mathrm{~mm})$, showed relatively more intense hBD-2 immunoreactivity as compared with untreated cells, IgG controls, or cells treated individually with MUC2, IL-1 $\beta$, or ATP (Figure 3).

To confirm specificity for MUC2 in regulating hBD-2, we used a high mucin-producing clone of HT-29 (clone HT-29 C16 $)^{20}$ designated MUC2 $\mathrm{H}$ and a derivate clone silenced for MUC2 by short hairpin RNA (shRNA) designated MUC2 L. MUC2 L showed 90\% reduction in MUC2 mRNA expression as compared with MUC2 $\mathrm{H}$ cells with no significant concomitant compensatory effects on MUC5AC and MUC5B mRNA expression (Supplementary Figure S2A). As predicted, MUC2 $\mathrm{H}$ expressed higher basal hBD-2 mRNA levels (Figure $4 \mathbf{a}, \mathbf{c}, \mathbf{d}$ ), and stimulation with 20 or $30 \mathrm{ng} \mathrm{ml}^{-1}$ of IL-1 $\beta$ for $16 \mathrm{~h}$ induced significantly elevated hBD-2 mRNA expression (eightfold change) as compared with MUC2 L cells (Figure 4a). These data were corroborated by immunofluorescence studies that demonstrated higher basal levels of intracytoplasmic accumulation of hBD-2 in MUC2 $\mathrm{H}$ cells that increased after stimulation with IL-1 $\beta\left(20 \mathrm{ng} \mathrm{ml}^{-1}\right)$ for $16 \mathrm{~h}$ (Figure $4 \mathbf{b}$ ). The hBD-2 mRNA levels or peptide cytoplasmic accumulation was absent or low in resting or IL- $1 \beta$-stimulated MUC2 L cells (Figure 4a,b). Stimulation with $20 \mathrm{~mm}$ of sodium butyrate $(0-40 \mathrm{~mm})$ for $16 \mathrm{~h}$ induced modest hBD-2 mRNA expression in MUC2 $\mathrm{H}$ cells (threefold change; Figure 4c), whereas stimulation with ATP $(0-10 \mu \mathrm{M})$ did not affect hBD-2 mRNA levels in neither MUC2 $\mathrm{H}$ nor MUC2 L cells (Figure 4d).

\section{MUC2 mucin allows pathogenic and nonpathogenic E. coli to resist the antimicrobial effects of $\beta$-defensin 2}

Human hBD-2 has broad antimicrobial effects against Grampositive and Gram-negative bacteria, ${ }^{23}$ and thus it was of interest to determine whether MUC2 mucin could regulate the activity of hBD-2 against commensal and/or pathogenic bacteria. As shown, nonpathogenic E. coli (HB101; Figure 5a) and EPEC (Figure 5b) were killed with as little as $1 \mu \mathrm{M}$ of hBD-2, whereas the probiotic anaerobe Bacteroides vulgatus (Figure 5c) and pathogenic Clostridium difficile (Figure 5d) were resistant even at concentrations up to $4 \mu \mathrm{m}$. Interestingly, increasing the concentration of MUC2 mucin allowed E. coli to survive under otherwise lethal dosages of hBD-2 (Figure 5a,b). To exclude the possibility of steric interference and specificity for MUC2 mucin, we used pig gastric mucin at equimolar concentrations as MUC2 and showed partial protection at inhibiting E. coli against hBD-2 (Figure 5a,b). In particular, higher concentrations of MUC2 mucin $(100 \mu \mathrm{g})$ significantly protected E. coli against hBD-2, whereas pig gastric mucin did not (Figure 5a,b). MUC2 mucin had no effect against B. vulgatus (Figure 5c) and C. difficile (Figure 5d). As the antimicrobial effect of cationic peptides such as hBD-2 on E. coli is mostly based on the capacity to cause membrane pore 

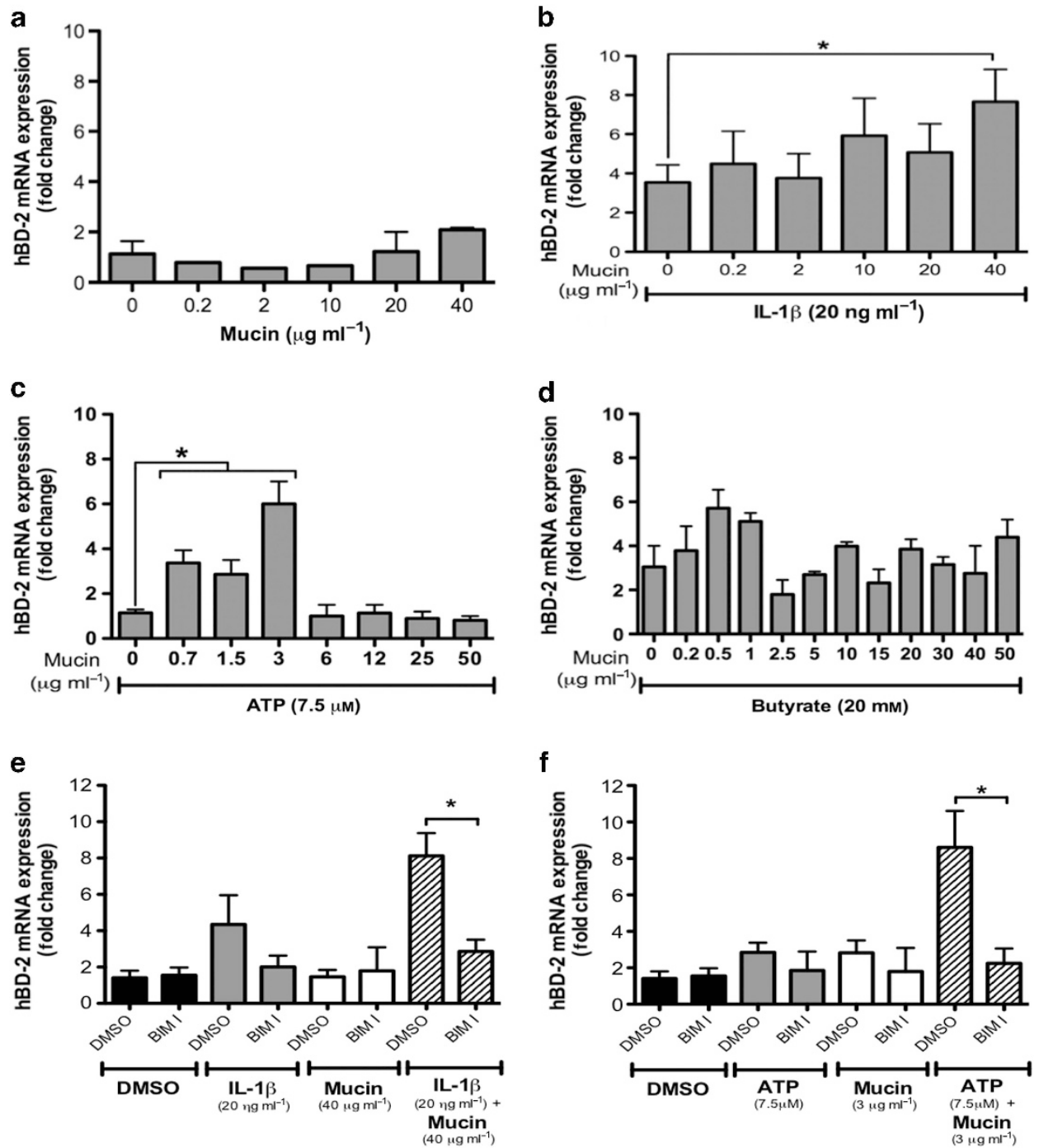

Figure 1 Interleukin-1 $\beta$ (IL-1 $\beta$ ) and adenosine triphosphate (ATP) but not butyrate stimulate $\beta$-defensin expression in the presence of MUC2 mucin. HT-29 cells were incubated with increasing concentrations of (a) purified secreted colonic MUC2 mucin or in combination with either (b) IL-1 $\beta$ $\left(20 \mathrm{ng} \mathrm{ml}^{-1}\right)$, (c) ATP $(7.5 \mu \mathrm{m})$, or (d) butyrate $(20 \mathrm{~mm})$ for $16 \mathrm{~h}$ in serum-free medium. HT-29 cells were preincubated with the protein kinase C (PKC)

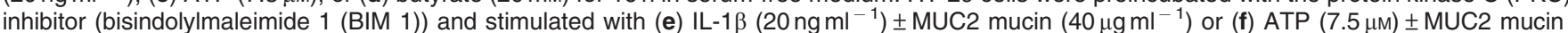
$\left(3 \mu \mathrm{g} \mathrm{ml}^{-1}\right)$ for $16 \mathrm{~h}$ in serum-free medium. HT-29 cells incubated with MUC2 mucin for up to $16 \mathrm{~h}$ remained viable as revealed by Trypan blue exclusion assay. Expression of human $\beta$-defensin 2 (hBD-2) mRNA was quantified by real-time quantitative reverse transcription PCR (real-time qRT-PCR) and represented as fold change relative to the housekeeping gene. DMSO, dimethyl sulfoxide. Samples were done in triplicates and the experiments were repeated twice. Data were analyzed by one-way analysis of variance (ANOVA) and post Tukey's multiple comparison tests were run to determine significant differences among groups. $P$-values for all significant comparisons with control $\left({ }^{\star} P<0.05\right)$ are represented.

formation and ultrastructural alterations, ${ }^{24}$ we investigated whether MUC2 mucin could prevent defensin-induced damage. To do this, EPEC was treated with hBD-2 and/or MUC2 mucin, and scanning electron microscopy showed that untreated bacteria (Figure 6a) or bacteria treated with MUC2 mucin alone (Figure 6b) or simultaneously with MUC2 mucin and hBD-2 (Figure 6d) showed normal rod-shaped elongated bacteria with smooth intact surfaces. In stark contrast, E. coli exposed to hBD-2 alone showed shortened and severe membrane alterations (Figure 6d), including multiple protrusions, dimples, and blisters on the surface (Figure 6e) that eventually ended in shrunken and dead bacteria in a debris field (Figure 6f). Microscopic quantification of 100 bacteria exposed to hBD-2 alone showed significant $(P<0.05)$ signs of membrane damage as compared with bacteria treated with hBD-2 + MUC2 mucin or MUC2 mucin alone or those that were left untreated.

The role of colonic mucin favoring bacterial growth was confirmed ex vivo by coculturing EPEC with crude colonic mucosal contents of mice. In this assay, colonic luminal secretions from $\mathrm{Muc2}^{+/+}$and $\mathrm{Muc2}^{+/-}$but not from $M u c 2^{-/-}$mice significantly increased the number of surviving E. coli after incubation for $2 \mathrm{~h}$ (Figure 7a). To investigate the length of time that MUC2 needed to be in contact with hBD-2 

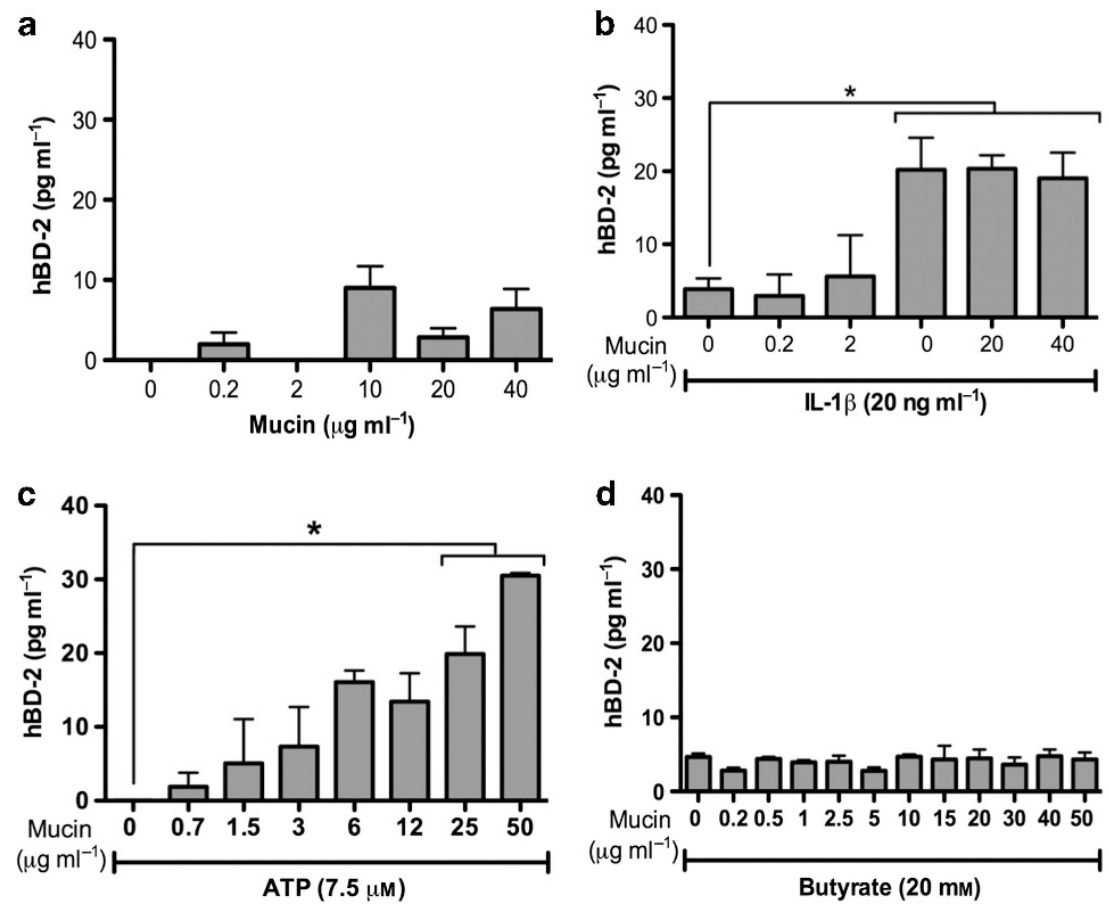

Figure 2 Interleukin-1 $\beta$ (IL-1 $\beta$ ) and adenosine triphosphate (ATP) but not butyrate stimulate $\beta$-defensin secretion in the presence of MUC2 mucin HT-29 cells were incubated with (a) purified secreted colonic MUC2 mucin only or in combination with either (b) IL-1 $\beta\left(20 \mathrm{ng} \mathrm{ml}{ }^{-1}\right)$, (c) ATP $(7.5 \mu \mathrm{m})$, or (d) butyrate $(20 \mathrm{~mm}$ ) for $16 \mathrm{~h}$ in serum-free medium as detailed in Figure 1. Secretion of human $\beta$-defensin 2 (hBD-2) peptide was quantified by enzymelinked immunosorbent assay (ELISA) from the supernatants of colonic cells. Samples were duplicated and experiments were replicated at least two times. One-way analysis of variance (ANOVA) and post Tukey's multiple comparison tests were run to determine significant differences among groups. $P$-values for all significant comparisons with control $\left({ }^{\star} P<0.05\right)$ are represented.
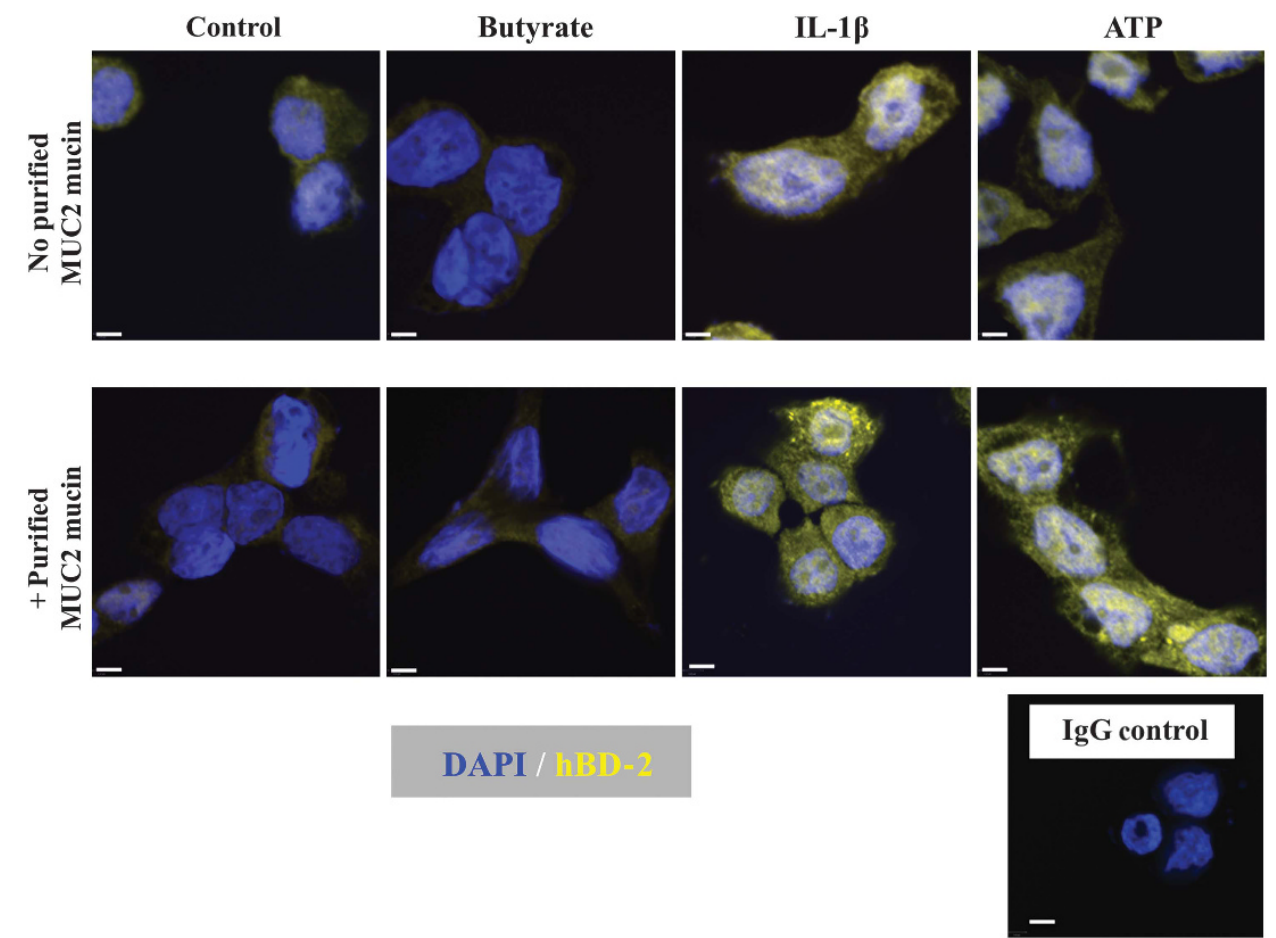

Figure 3 Confocal intracellular localization of $\beta$-defensin induced by interleukin-1 $\beta$ (IL-1 $\beta$ ), adenosine triphosphate (ATP), and MUC2 mucin in colonic cells. HT-29 cells were incubated with IL-1 $\beta\left(20 \mathrm{ng} \mathrm{ml}^{-1}\right)$, ATP $(7.5 \mu \mathrm{M})$, or butyrate $(20 \mathrm{~mm})$ only (upper panel) or in combination with MUC2 mucin $\left(20 \mu \mathrm{g} \mathrm{ml}^{-1}\right.$, lower panel) for $16 \mathrm{~h}$ in serum-free medium. $\beta$-Defensin was stained with an antibody against anti-hBD-2 (yellow) and the nucleus with 4',6-diamidino-2-phenylindole (DAPI; blue). Image is from one of four independent experiments. Scale bar $=10 \mu \mathrm{m}$. 
a

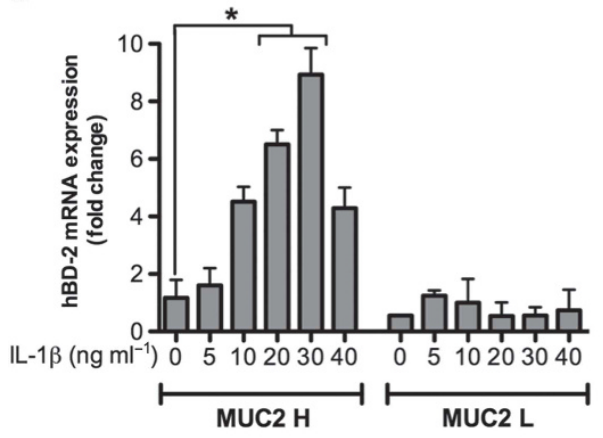

b

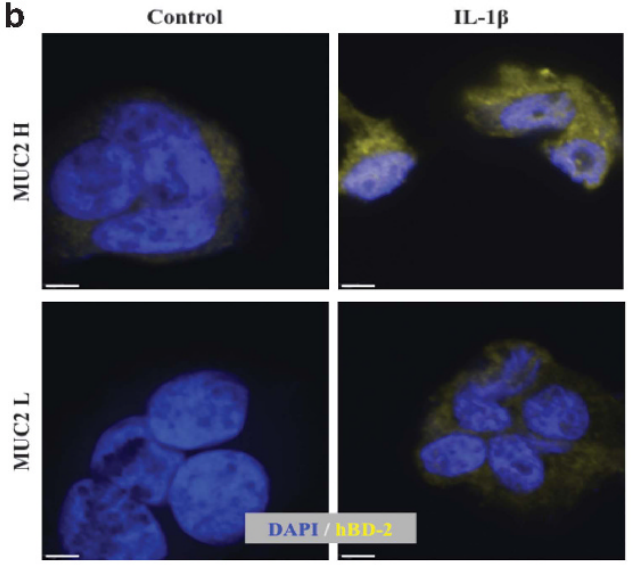

C

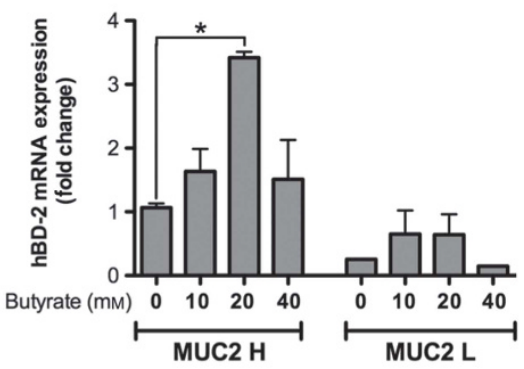

d

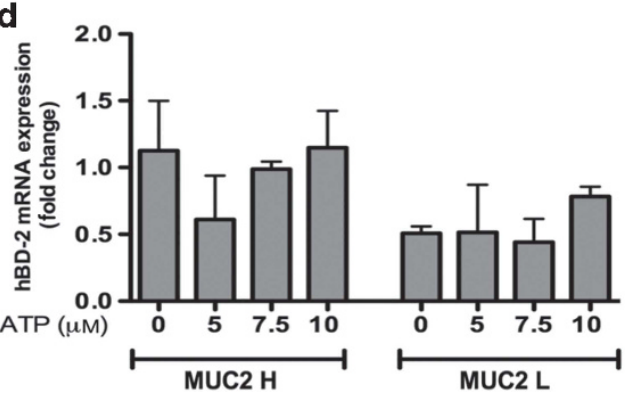

Figure 4 Interleukin-1 $\beta$ (IL-1 $\beta$ ) and butyrate stimulate human $\beta$-defensin 2 (hBD-2) in high MUC2-producing colonic cells. HT-29 H and L cells were incubated with $(\mathbf{a}, \mathbf{b}) \mathrm{IL}-1 \beta,(\mathbf{c})$ butyrate, or (d) adenosine triphosphate (ATP) for $16 \mathrm{~h}$ in serum-free medium. (a, c, d) Expression of hBD-2 mRNA was quantified by real-time qRT-PCR and represented as fold change relative to the housekeeping gene. Samples were triplicated and experiments were replicated at least two times. One-way analysis of variance (ANOVA) and post Tukey's multiple comparison tests were run to determine significant differences among groups. $P$-values for all significant comparisons with control $\left({ }^{\star} P<0.05\right)$ are represented. (b) $\mathrm{HT}-29 \mathrm{H}$ and $\mathrm{L}$ cells were incubated with $\mathrm{IL}-1 \beta\left(20 \mathrm{ng} \mathrm{ml}^{-1}\right)$ for $16 \mathrm{~h}$ and $\beta$-defensin was stained with antibody anti-hBD-2 (yellow) and nucleus with 4',6-diamidino-2-phenylindole (DAPI; blue). Image is from one of four independent experiments. Scale bar $=10 \mu \mathrm{m}$.

to abrogate its antimicrobial effects, EPEC was exposed to hBD-2 and MUC2 mucin simultaneously for up to $60 \mathrm{~min}$ (Figure 7b). As shown, although the number of EPEC steadily increased in the presence of MUC2 either with or without hBD-2, hBD-2 alone gradually killed E. coli in the first $60 \mathrm{~min}$ in the absence of MUC2 (Figure $7 \mathbf{b}$ ).

\section{MUC2 oligosaccharides are the determinant of bacterial antimicrobial protection and $\beta$-defensin induction}

Mucin O-linked glycans make up $\sim 80 \%$ of the MUC2 mucin mass that serves as binding sites for bacteria. ${ }^{25,26}$ Thus, to determine the importance of MUC2 oligosaccharide moieties in protecting bacteria against $\beta$-defensin, mucin carbohydrates were disrupted by gentle oxidization with sodium metaperiodate that cleaves adjacent carbon atoms that contain hydroxyl groups (cis-glycols). As predicted, alterations of MUC2 glycans and perhaps some amino acids by oxidation significantly abrogated the protective effects of MUC2, allowing hBD-2 to effectively kill EPEC (Figure 8a) as compared with untreated MUC2. The role of mannose and sialic acid mucin residues in protecting bacteria from hBD-2 was also investigated because mannose-type $\mathrm{N}$-linked oligosaccharides of rat and rabbit intestinal mucin serve as binding sites for E. coli O157:H7 expressing type 1 mannose-sensitive fimbriae $e^{26,27}$ and intestinal mucin oligomannosyl receptors for type 1 pili are covered by noncovalently bound lipid that may involve terminal sialic acid residues. ${ }^{27}$ Surprisingly, mannose and sialic acid residues on MUC2 did not significantly protect bacteria against hBD-2, as enzymatic removal of these oligosaccharides did not reduce the number of surviving EPEC in the presence of $1 \mu \mathrm{M}$ of hBD-2 (Figure 8b). Interestingly, MUC2 mucin oligosaccharides were also found to be critically important in regulating $\beta$-defensin as the addition of oxidized MUC2 mucin induced significantly lower hBD-2 mRNA expression (Figure 8c) and peptide release (Figure 8d) in HT-29 cells simultaneously stimulated with IL-1 $\beta$ as compared with native untreated MUC2. To determine the physical interactions between mucin and $\beta$-defensin, we coated enzyme-linked immunosorbent assay (ELISA) plates with purified MUC2 mucin and quantified the binding of recombinant hBD-2. Regardless of the concentration of MUC2 used, there was no significant increase in the binding of hBD-2 toward immobilized MUC2 (Supplementary Figure S2B).

Muc2-deficient mice have reduced $\beta$-defensin expression To determine the importance of the colonic mucin barrier in the production of defensins, we investigated the expression and production of $\beta$-defensins in the mucosa of the proximal colon 
a

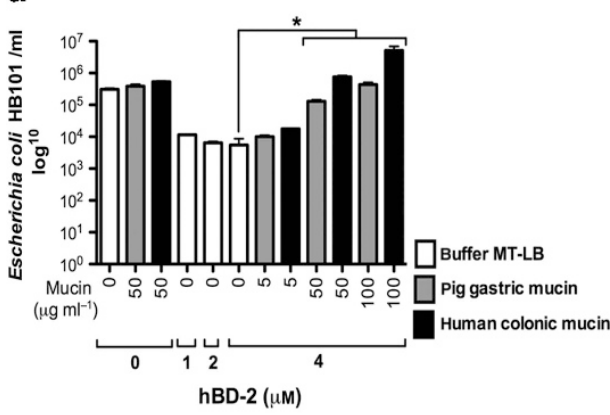

C

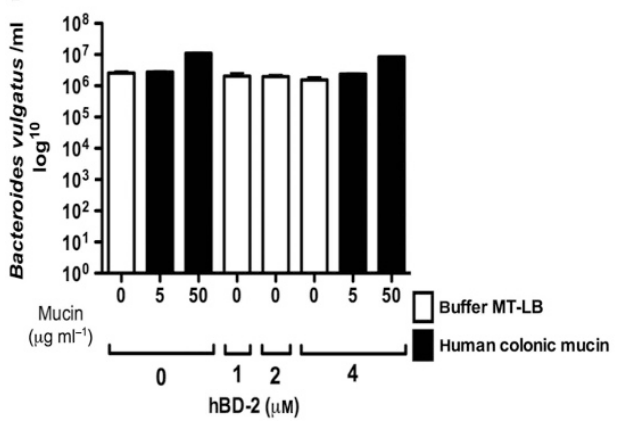

b

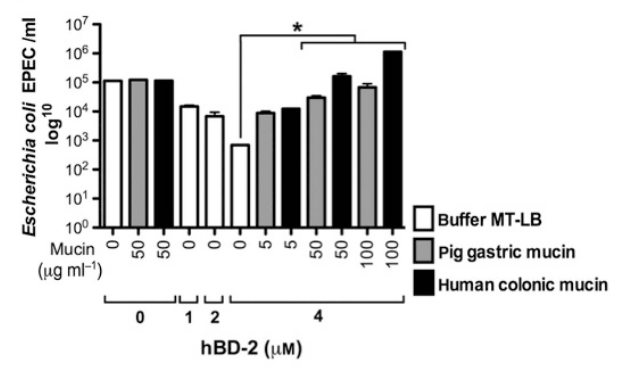

d

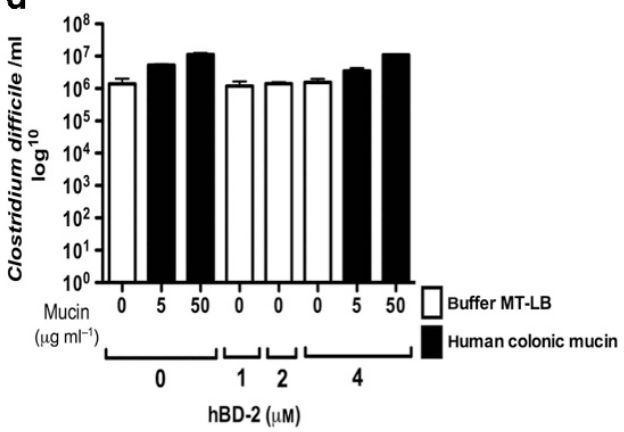

Figure 5 The survival of enteric commensal and pathogenic bacteria against hBD-2 in the presence of MUC2 mucin. MUC2 mucin abrogated the antimicrobial effects of human $\beta$-defensin 2 (hBD-2) in otherwise susceptible (a) nonpathogenic HB101 Escherichia coli and (b) enteropathogenic Escherichia coli (EPEC). (c) Commensal Bacteroides vulgatus and (d) pathogenic Clostridium difficile were resistant to antimicrobial effects of hBD-2. Bacteria were incubated in control MT-LB buffer only or in combination with hBD-2 and/or pig gastric or human MUC2 mucin for $2 \mathrm{~h}$. The numbers of surviving colony-forming units (CFUs) were quantified by measuring bacterial adenosine triphosphate (ATP) and represented by the logarithm to base 10 $\left(\log ^{10}\right)$. Samples were triplicated and experiments were replicated at least three times. One-way analysis of variance (ANOVA) and post Tukey's multiple comparison tests were run to determine significant differences among groups. $P$-values for all significant comparison with control $\left({ }^{\star} P<0.05\right)$ are represented.
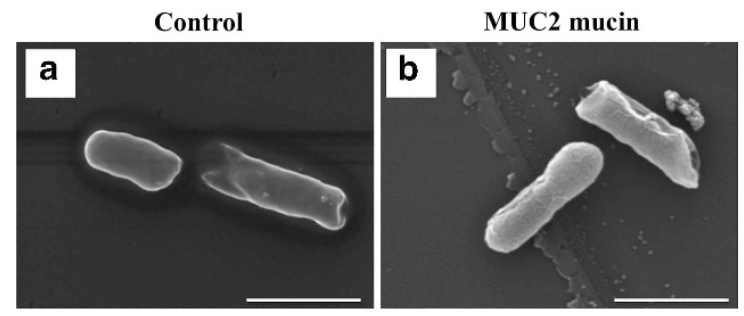

hBD-2 + MUC2 mucin
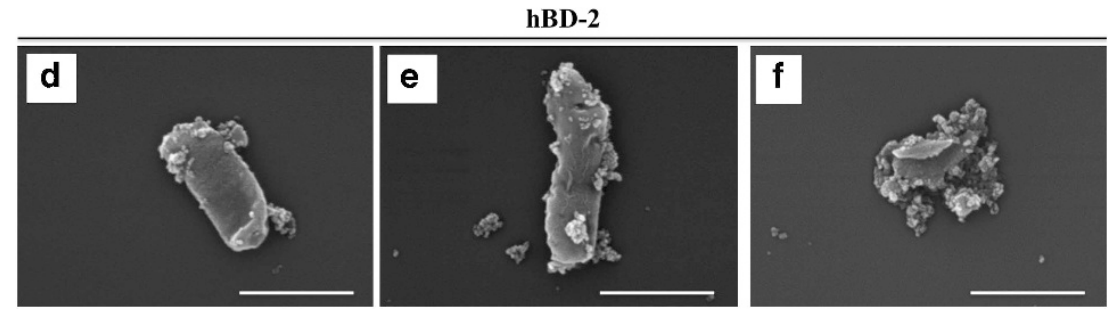

Figure 6 Scanning electron microscopy micrographs of enteropathogenic Escherichia coli (EPEC) demonstrating that colonic MUC2 mucin inhibited bacterial membrane damage induced by human $\beta$-defensin 2 (hBD-2). EPEC were incubated in (a) control MT-LB buffer, (b) MUC2 mucin (20 $\mu \mathrm{g} \mathrm{ml}{ }^{-1}$ ), (c) MUC2 mucin plus hBD-2 $(2 \mu \mathrm{m})$, or (d-f) hBD-2 $(2 \mu \mathrm{m})$ alone for $2 \mathrm{~h}$. (c) Bacteria incubated with MUC2 plus hBD-2 were protected against membrane damage from hBD-2 as shown in $\mathbf{d}-\mathbf{f}$. Bacteria incubated with hBD-2 alone show bacterial contraction with (d, e) membrane blebbing and (f) bacterial debris. Images are from 1 of 10 independent experiments. Scale bar $=1 \mu \mathrm{m}$.

of $\mathrm{Muc2}^{+/+}$and $\mathrm{Muc2} 2^{+/-}$mice with a well-defined and intact mucus layer and in $\mathrm{Muc2}^{-/-}$littermates in the absent of mucus (Figure 9a). $\beta$-defensin peptide was distributed uniformly along the lumen and apical surface of the colonic cells and not restricted to goblet cells in the mucosa of $\mathrm{Muc2}^{+/+}$and $\mathrm{Muc2}^{+/-}$mice (Figure $9 \mathrm{~b}$ and Supplementary Figure S2C), whereas it was 


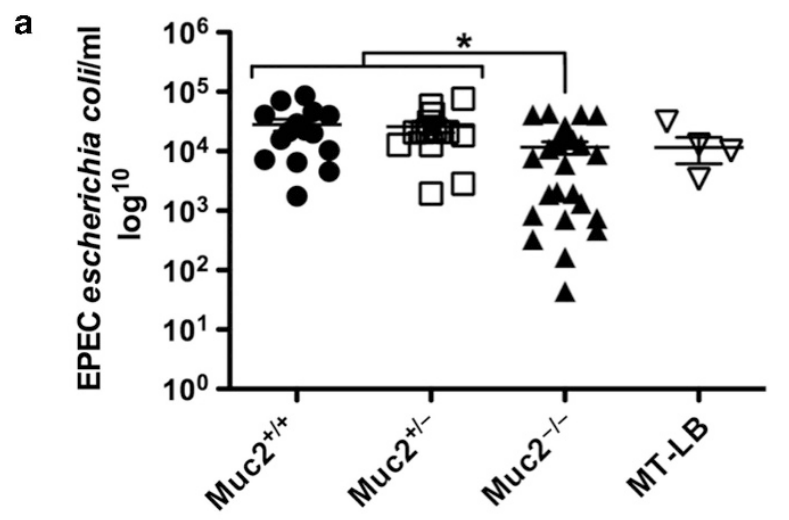

b

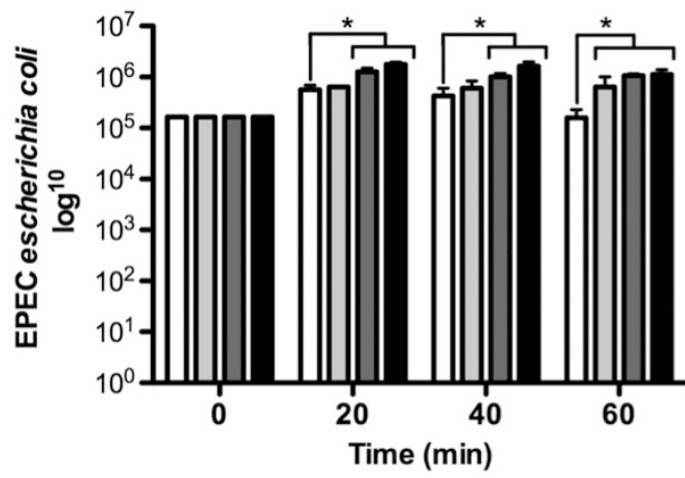

$\square \mathrm{hBD}-2+$ no MUC2 mucin No hBD-2 + no MUC 2 mucin

hBD-2 + MUC2 mucin No hBD-2 + MUC2 mucin

Figure 7 The survival of $\mathrm{E}$. coli against hBD-2 in the presence of colonic contents or purified MUC2 mucin. (a) Colonic contents from mice with an intact mucin barrier enhance the growth of Escherichia coli. Enteropathogenic Escherichia coli (EPEC) were incubated with luminal mucosal contents derived from the colons of $\mathrm{MuC2}^{+/+}, \mathrm{MuC2}^{+/-}$, and Muc2 $^{-/-}$littermates (total $20 \mu \mathrm{g}$ protein) or control MT-LB buffer for $2 \mathrm{~h}$. $P$-values for all significant comparisons $\left({ }^{\star} P<0.05\right)$ are represented. (b) In vitro coculture of EPEC with human $\beta$-defensin 2 (hBD-2; $2 \mu \mathrm{M})$ and MUC2 mucin $\left(20 \mu \mathrm{g} \mathrm{ml}^{-1}\right)$ for $1 \mathrm{~h}$ revealed that mucin rapidly protects bacteria against the antimicrobial effects of $\beta$-defensin. The numbers of surviving colony-forming units (CFUs) were quantified by measuring bacterial adenosine triphosphate (ATP) and represented by the logarithm to base $10\left(\log ^{10}\right)$. Samples were triplicated and experiments were replicated at least three times. One-way analysis of variance (ANOVA) and post Tukey's multiple comparison tests were run to determine significant differences among groups. $P$-values for all significant comparisons $\left({ }^{\star} P<0.05\right)$ are represented.

restricted to a minimum presence in the colonic lumen of $M u c 2^{-/-}$littermates (Figure 9b). Similarly, basal mRNA expression of $\beta$-defensin 4 (orthologous of hBD-2) 28,29 $^{2}$ and 14 (orthologous of $\mathrm{hBD}-3)^{30}$ was significantly reduced in the colonic mucosa of $M u c 2^{-/-}$mice as compared with $M u c 2^{+/-}$ and $\mathrm{Muc2}^{+/+}$littermates (Figure 9c,d).

\section{DISCUSSION}

Our results unraveled an important regulatory role for MUC2 mucin in hBD-2 mRNA and peptide production in a proinflammatory milieu. The hBD-2 mRNA expression, peptide release, and intracellular localization in colonic HT-29 cells that constitutively express low mucin ${ }^{20,21}$ was enhanced following stimulation with the proinflammatory cytokine IL-1 $\beta$ and/or ATP in association with exogenously added colonic MUC2 mucin. The MUC2 mucin used in this study purified from colonic LS $174 \mathrm{~T}$ cells $^{31}$ contained very high levels of immunoreactive MUC2. Although the presence of small amounts of contaminating proteins in this preparation cannot be excluded, our studies showed no major contaminating proteins visualized by silver staining and no immunoreacitve MUC5AC or MUC5B. The participatory role of MUC2 in inducing $\beta$-defensin was confirmed using high MUC2-producing HT-29 cells where IL-1 $\beta$ increased hBD- 2 mRNA expression and intracellular peptide accumulation. Previous studies have shown that hBD-2 expression was upregulated in the colonic epithelium in response to IL- $1 \beta,{ }^{5,32}$ but as shown in our study, $\beta$-defensin induction by IL-1 $\beta$ may require a healthy MUC2 mucin barrier. Although the synergistic mechanism between MUC2 and defensins is still unknown, we found that MUC2 oligosaccharides facilitated the induction of $\beta$-defensin as alteration of MUC2 by oxidation impaired hBD-2 stimulation by IL-1 $\beta$. As sodium metaperiodate can also oxidize certain amino acids, we cannot exclude those as having an effect in our study. This study also shows that ATP in combination with MUC2 mucin could induce $\beta$-defensins in colonic cells. This is important as extracellular ATP, either from stressed, injured, or necrotic intestinal cells ${ }^{15}$ or from bacteria, ${ }^{17}$ constitutes a danger signal that, based on our finding, may regulate hBD-2 in the colon in coordination with MUC2 mucin. Similar amounts of intestinal extracellular ATP were noted in the intestine of mice with epithelial cells deficient in ectonucleoside triphosphate diphosphohydrolases. ${ }^{16}$ Thus, severe inflammation or necrosis or defect in ATP hydrolysis in the colon may induce enough extracellular ATP that induces hBD-2 in coordination with MUC2. Intestinal commensal bacteria can also produce luminal $\mathrm{ATP}^{17}$ but are insufficient at low concentrations to stimulate hBD-2 based on our findings. We also found a nonsynchronized dose response between hBD-2 mRNA and peptide secretion following stimulation with MUC2 and IL-1 $\beta$ / ATP. This implies differential mechanisms of expression and synthesis in response to the respective agonists and possible roles of ATP as a goblet cell secretagogue that increases the amount of mucin and the synergic effect. Furthermore, high doses of ATP may have a negative impact in MUC2 $\mathrm{H}$ cells to induce MUC2 production and it was dependent on the addition of exogenous mucin. Surprisingly, sodium butyrate, a physiological metabolite produced by colonic probiotic bacteria, showed only a limited effect on hBD-2 in MUC2 $\mathrm{H}$ cells, perhaps as a result of the ability of butyrate to induce cell differentiation and the production of even more MUC2, but it was refractory to further stimulation with exogenously added MUC2. We speculate that hBD-2 was not induced by butyrate as a mechanism to prevent exaggerated or harmful reactions to the normal microbiota. In agreement, sodium butyrate was shown to exhibit other anti-inflammatory functions, by inhibiting the expression of proinflammatory cytokines. ${ }^{33}$ The hBD-2 mRNA expression in response to MUC2 and IL-1 $\beta$ / ATP in colonic epithelial cells was regulated by $\mathrm{PKC}$ based on complete inhibition with the PKC inhibitor (bisindolylmaleimide 1 (BIM 1)). The PKC signaling pathway and regulation of 
a
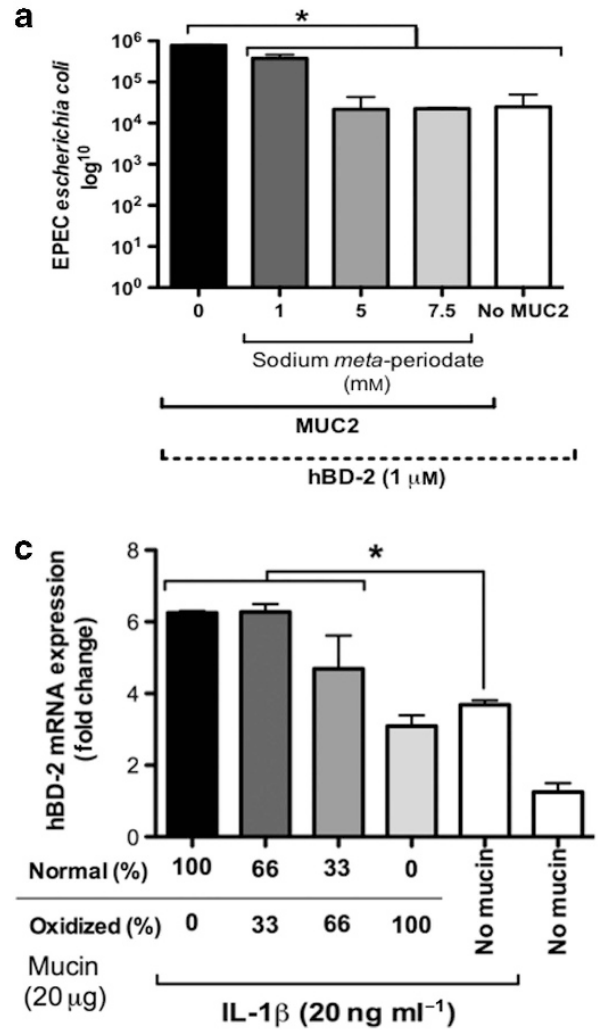

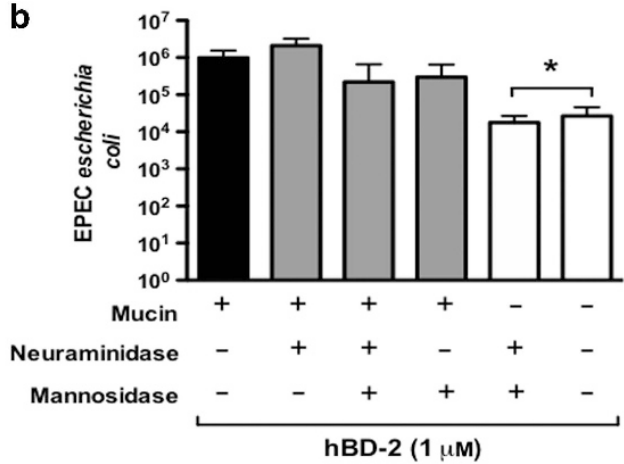

d

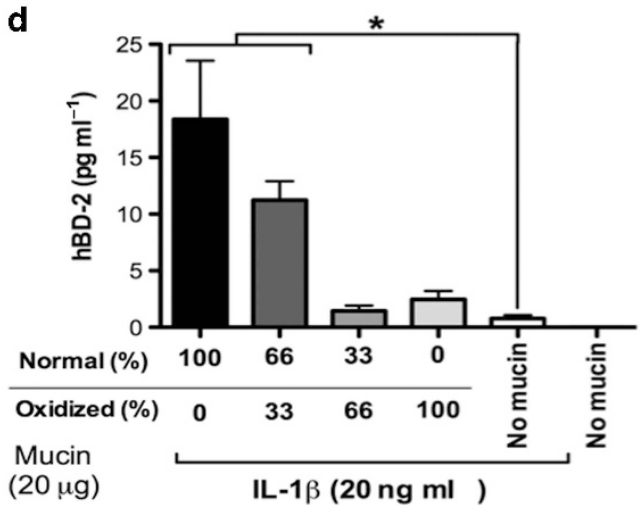

Figure 8 Mucin oligosaccharide moieties are critical in regulating $\beta$-defensin induction and in protecting bacteria. Enteropathogenic Escherichia coli (EPEC) were incubated with (a) human $\beta$-defensin 2 (hBD-2; $1 \mu \mathrm{m})$ or with MUC2 mucin $\left(20 \mu \mathrm{g} \mathrm{ml}^{-1}\right)$ oxidized by sodium metaperiodate or (b) enzymatically cleaved of sialic acid and mannose. The numbers of surviving colony-forming units (CFUs) were quantified by measuring bacterial adenosine triphosphate (ATP) and represented by the logarithm to base $10\left(\log ^{10}\right)$. $P$-values for all significant comparison with no mucin control $\left({ }^{\star} P<0.05\right)$ are represented. (c) Expression of hBD-2 mRNA quantified by real-time qRT-PCR and represented as fold change relative to the housekeeping gene, and (d) hBD-2 peptide release measured by enzyme-linked immunosorbent assay (ELISA) was determined in HT-29 cells stimulated with interleukin-1 $\beta$ (IL-1 $\left.\beta ; 20 \mathrm{ng} \mathrm{ml}^{-1}\right)$ and native or oxidized MUC2 mucin $\left(20 \mu \mathrm{g} \mathrm{ml}^{-1}\right)$. Samples were triplicated and experiments were replicated at least two times. One-way analysis of variance (ANOVA) and post Tukey's multiple comparison tests were run to determine significant differences among groups. $P$-values for all significant comparisons with control cells without IL-1 $\beta\left({ }^{\star} P<0.05\right)$ are represented.

nuclear factor (NF)- $\mathrm{\kappa B}$ have been implicated in the expression of hBD-2 in human lung epithelial cells (A549) stimulated with IL-1 $\beta .^{34}$ The involvement of diacyl glycerol and calciumresponsive $\mathrm{PKC}$ and NF- $\mathrm{KB}$ in the regulation of $\mathrm{hBD}-2$ seems to be common to various stimuli as it was also reported in mononuclear phagocytes in response to lipopolysaccharide ${ }^{35}$ and A549 cells infected with Mycobacterium bovis bacillus Calmette-Guerin. ${ }^{36}$ At present, we do not know the exact mechanism of how exogenous MUC2 mucin regulates hBD-2 mRNA expression. On possible explanation is that MUC2 glycans are interacting with epithelial cell lectin to exert its functional effects. Although $\mathrm{PKC} / \mathrm{NF}-\kappa \mathrm{B}$ mechanisms are expected for IL-1 $\beta$, ATP in synergy with mucin seems also to be at least, in part, mediated through activation of similar signaling proteins.

Our in vivo mouse model underscores the importance of MUC2 for proper $\beta$-defensin stimulation as Muc2-deficient animals expressed less $\beta$-defensin mRNA and peptide expression than heterozygous and wild-type (WT) littermates with an intact mucin barrier. The reduced baseline production of $\beta$-defensin in Muc2-deficient mice correlates with an impaired response to proinflammatory mediators (e.g., IL-1 $\beta$ ) as showed in vitro in human colonic MUC2 L cells (Figure 4). Altered colonic $\beta$-defensin expression with decreased antimicrobial capacity was also described in Nlrp3-deficient mice in a dextran sulfate sodium colitis model. ${ }^{37}$ Other host antimicrobial peptides may respond distinctively in the colon of $\mathrm{Muc}^{-1-}$ mice as the expression of cathelicidins did not differ among $M u c 2^{-1-}$ and WT mice, ${ }^{38}$ whereas the expression of antimicrobial C-type lectin Reg3b, Reg3c, and Ang4 peptides was higher in the distal colon of $\mathrm{Muc2}^{-1-}$ compared with WT but similar in the proximal colon. ${ }^{39}$ The Muc2-deficient murine model is relevant to study the biology of mucin in epithelial barrier function and the influence of MUC2 in the expression of host defense peptides. This intestinal mucin model suggests that the patched and incomplete adherent mucus gel seen in ulcerative colitis ${ }^{10,11}$ accompanied by high proinflammatory cytokines (e.g., IL-1 $\beta$ ) can increase the expression of hBD-2 in epithelial cells. ${ }^{8,9}$

At the functional level, we found that MUC2 mucin protected enteric bacteria from the antimicrobial effect of $\beta$-defensin. EPEC and nonpathogenic E. coli are highly 

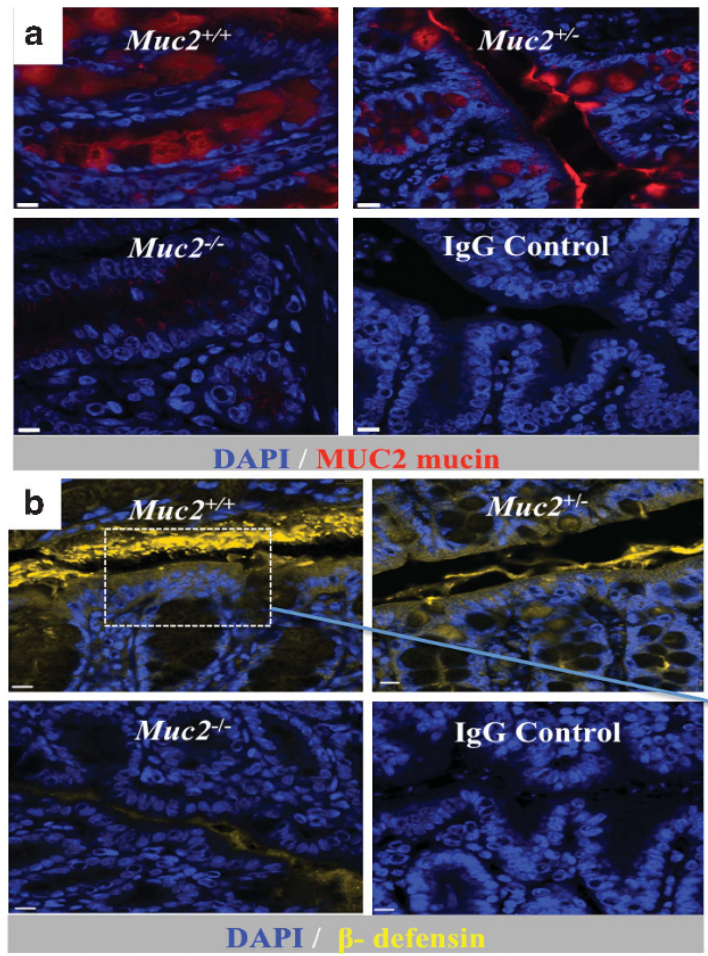

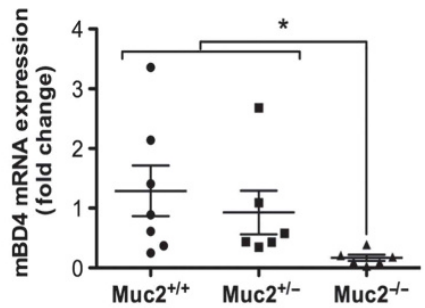

d
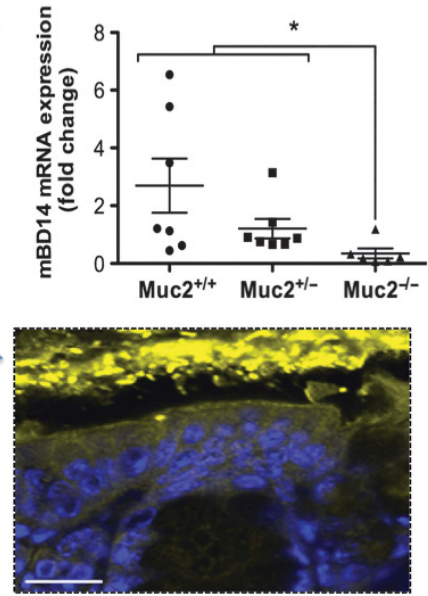

Figure $9 \beta$-Defensins are downregulated in Muc2-deficient mice. Confocal immunolocalization of $(\mathbf{a})$ mucin and (b) $\beta$-defensin peptides in the mucosa of the proximal colon of $\mathrm{MuC2}^{+/+}, \mathrm{MuC2}^{+/-}$, and $\mathrm{MuC2}^{-/-}$littermates with antibodies against MUC2 (red) and anti- $\beta$-defensin 2 (yellow). Rabbit lgG was used as controls. Nuclei were stained with 4',6-diamidino-2-phenylindole (DAPI; blue). Image is from one of five independent experiments. Scale bar $=30$ and $10 \mu \mathrm{m}$ for insert. Basal expression of (c) $\beta$-defensin 4 and (d) $\beta$-defensin 14 was quantified by real-time qRT-PCR in the colonic mucosa of $\mathrm{Muc2}^{+/+}, \mathrm{MuC2}^{+/-}$, and $\mathrm{Muc2}^{-/-}$littermates and expressed as fold change relative to actin the housekeeping gene. Experiments were replicated at least three times. One-way analysis of variance (ANOVA) and post Tukey's multiple comparison tests were run to determine significant differences among groups. $P$-values for all significant comparisons $\left({ }^{*} P<0.05\right)$ are represented.

susceptible to $\mathrm{hBD}-2$, yet they survived in the presence of MUC2 mucin. Importantly, we showed that bacterial membrane alterations and subsequent death caused by the electrostatic interactions between cationic $\beta$-defensin and negatively charged surface of EPEC were inhibited in the presence of MUC2 mucin. Bacteria and mucin association was likely determined by bacterial lectins with high affinity for MUC2 $\mathrm{N}$ - and $\mathrm{O}$-linked oligosaccharides receptors as the protective effects of mucin was abrogated following sodium metaperiodate oxidation. This agrees with studies in ulcerative colitis patients with an impaired mucus layer that showed severely reduced population of Enterobacteriaceae mostly represented by commensal E. coli. ${ }^{40}$ In addition, MUC2 mucin allowed the survival of hBD-2-resistant bacteria, including commensal $B$. vulgatus and $C$. difficile, the causative agent of antibiotic-associated diarrhea and pseudomembranous colitis. ${ }^{40}$ Thus, defects in the colonic mucin layer may favor the growth of microbes that resist $\beta$-defensin (e.g., $C$. difficile) over bacteria vulnerable to $\beta$-defensin that survived because of the protective effects of mucin. In agreement, $C$. difficile is more prevalent in patients with ulcerative colitis that have a thinner or depleted mucin layer with concomitant worst prognosis and mortality. ${ }^{41,42}$ The beneficial effect of colonic mucin on bacterial growth was confirmed ex vivo in which EPEC increased in numbers in the presence of the colonic contents of $\mathrm{Muc2}^{+/-}$and $\mathrm{Muc2}^{+/-}$but remained stable when cocultured with the colonic contents of $\mathrm{Muc}^{-1-}$ mice. Although the crude mucosal preparations from $\mathrm{Muc2}^{+/+}$ and $\mathrm{Muc2}^{-1-}$ littermates may contain other inflammatory factors (e.g., reactive oxygen species) that could influence bacterial growth, our findings agree with studies where cationic peptide extracted from colonic biopsies from patients with ulcerative colitis with an impaired mucin layer were more effective at killing B. vulgatus and E. coli compared with colonic contents from patients with Crohn's disease with a preserved mucin layer. ${ }^{43}$

Mechanistically, we showed that MUC2 mucin quickly protected E. coli against a lethal dose of hBD-2 (30-60 min bacteria). This rapid protection was needed as hBD-2 by itself or in association with lysozymes can disrupt bacterial membranes as early as at $30 \mathrm{~min} .{ }^{44}$ Other complex carbohydrates found in the gastrointestinal lumen may also confer partial protective effects on bacteria as E. coli partially survived hBD-2 in the presence of equimolar concentrations of mucin preparation from pig stomach. The crude pig gastric mucin likely contains MUC5AC, MUC6, as well as other glycoproteins (not specified by the manufacturer). Hypothetically, the antimicrobial activity of defensin peptides could be blocked 
by electrostatic interactions with mucin in the outer mucin layer that harbors commensal bacteria. In support of this, hBD-1 and hBD-3 were shown to be bound to rectal mucus extracts and had partially reduced antimicrobial efficacy. ${ }^{45}$ Thus, an impaired mucin layer may lead to more free active antimicrobial peptides, although the lack of MUC2 will progressively affect proper hBD-2 stimulation. However, colonic MUC2 mucin, unlike rectal mucus, did not bind hBD-2, at least under in vitro condition. We hypothesize that the "protective effect" of MUC2 is because bacteria use it as source of energy that can overcome the killing effect of hBD-2. This is based on increased bacterial growth in the presence of MUC2 only or with MUC2/hBD-2 in combination (Figure 5a,b). Moreover, that bacteria is protected by MUC2 is shown by our studies in which periodate treatment abrogated the mucin protective effect and bacteria became more susceptible to be killed by hBD-2 (Figure 8a). Furthermore, the in vivo role of $\beta$-defensins in the colonic lumen may serve to prevent harmful inflammatory responses and not merely antimicrobial as exogenous cathelicidin (other major host defense peptide) reduced tissue levels of IL- $1 \beta$ and tumor necrosis factor- $\alpha$ in the colon of dextran sulfate sodium-challenged cathelicidin knockout $\left(\mathrm{Cramp}^{-/-}\right)$mice. $^{46}$ Taken together, our studies have unraveled a complex interplay at the mucosal surface of the colon where MUC2 mucin and antimicrobial $\beta$-defensin peptides regulate the microbiota. Colonic MUC2 provides a matrix to sustain $\beta$-defensin induction in the presence of IL- $1 \beta$ to functionally protect susceptible bacteria from the antimicrobial effects of $\beta$-defensin. Defective expression of MUC2 may modify the composition of the commensal microbiota by eliminating a major source of energy and exposing the normal microbiota to the lethal effects of $\beta$-defensin. Changes in microbiota composition plus the lack of MUC2 mucin that regulates induction of $\beta$-defensin could lead to opportunistic microbial invasion and/or impaired innate responses.

\section{METHODS}

Ethics statement. All studies were approved under the University of Calgary Animal Care Committee that adheres to the principles and policies on "Guide to the Care and Use of Experimental Animals" by the Canadian Council on Animal Care.

Purification of human colonic mucin. Secreted mucin was purified from human LS $174 \mathrm{~T}$ goblet cells as previously described. ${ }^{31}$ LS $174 \mathrm{~T}$ cells constitutively express and secrete high levels of MUC2 mRNA (four times more than HT-29) ${ }^{21}$ and low expression of MUC1 with no MUC3 or MUC4 ${ }^{47}$ and secrete high-density hexose-rich fractions rich in serine, threonine, and proline and $\mathrm{N}$-acetyl-galactosamine (GalNAc), $N$-acetlyglucosamine (GlcNAc), and galactose (Gal) typical of native secreted human colonic mucin. ${ }^{31}$ We used secreted rather than intracellular MUC2 mucin because it is native polymeric mucin and best represents the physiological mucus layer. Although it is difficult to predict whether the dosages of purified MUC2 $\left(3-50 \mu \mathrm{g} \mathrm{ml}^{-1}\right)$ used in our study are represented in vivo, the colon has a particularly thick mucus ge ${ }^{48}$ and is probably well within the concentrations used in our study. In brief, cell-free supernatants derived from $80 \%$ confluent cells were centrifuged $(300 \mathrm{~g})$ for $5 \mathrm{~min}$ at $4{ }^{\circ} \mathrm{C}$, dialyzed against deionized water $(12 \mathrm{~K}-14 \mathrm{~K}$ molecular weight cutoff, SpectraPor, SpectraLabs, Fisher Scientific, Whitby, ON, Canada), and lyophilized. Crude lyophilized mucus $(100 \mathrm{mg})$ was dissolved in Tris HCl buffer $(0.01 \mathrm{M})$ containing 0.001\% sodium azide ( $\mathrm{pH}$ 8.0; Sigma-Aldrich, Oakville, ON, Canada) and fractionated (100 mg per column) on an equilibrated Sepharose 4B gel filtration column $(2.5 \times 50 \mathrm{~cm}$; Bio-Rad Laboratories, Mississauga, ON, Canada) (column flow rate: $12 \mathrm{ml} \mathrm{h}^{-1}$ ). Highmolecular-weight mucin fractions in the void volume $\left(\mathrm{V}_{0}\right)(25-30)$ were pooled, dialyzed against deionized water $\left(4^{\circ} \mathrm{C}\right)$, and concentrated (SpinX UF 10K molecular weight, Corning, Fisher Scientific, Whitby, ON, Canada) (Supplementary Figure S1A). The $V_{0}$ mucin $(2 \mathrm{mg}$ ) was digested with DNase $(1 \mathrm{mg})$ and $\mathrm{RNase}(2 \mathrm{mg})$ and subjected to $\mathrm{CsCl}$ density gradient ultracentrifugation (starting density $1.41 \mathrm{~g} \mathrm{ml}^{-1}$ ) to purify MUC2 $\left(>1.46 \mathrm{~g} \mathrm{ml}^{-1}\right.$ ) (Supplementary Figure S1B). Fractions (1-8) were run on a $1.2 \%$ agarose gel under reducing conditions and western blotted with affinity-purified rabbit IgG anti$\mathrm{CsCl}$ purified LS 174T mucin (pooled fractions 6 and 7) antibody ${ }^{31}$ (Supplementary Figure S1C). Purified MUC2 $\mathrm{CsCl}$ fractions (fractions 6 and $7,1 \mu \mathrm{g}$ ) were run on a 1.2\% agarose gel and western blotted with affinity-purified rabbit polyclonal IgG MUC2 antibodies (as above) and MUC5AC mouse monoclonal antibody raised against M1 mucin preparation from the fluid of an ovarian mucinous cyst belonging to an O le (a-b) patient (Santa Cruz Biotechnology, Dallas, $\mathrm{TX}$ ) and an affinity-purified goat polyclonal antibody raised against a peptide mapping within an internal region of human MUC5B (Santa Cruz; Supplementary Figure S1D). Protein concentration was estimated using the BCA protein assay (Pierce, Thermo Scientific, Fisher Scientific, Whitby, ON, Canada). Sodium dodecyl sulfatepolyacrylamide gel electrophoresis $(7 \%)$ of Sepharose $4 \mathrm{~B} \mathrm{~V}_{\mathrm{o}}$ (from Supplementary Figure S1A) and cesium chloride density gradient centrifugation fraction 7 (from Supplementary Figure S1B) mucin were silver stained (Pierce, Thermo Scientific Silver Stain Kit, PI-24612) to visualize contaminating proteins and western blotted to visualize MUC2 (Supplementary Figure S1E).

Oxidative and enzymatic degradation of MUC2 mucin. Mucin was oxidized by sodium metaperiodate (Sigma) diluted in phosphatebuffered saline solution (PBS; $\mathrm{pH} 7.3$ ) on ice for $1 \mathrm{~h}$ in a dark room. ${ }^{49}$ Terminal sialic acid residues were degraded by neuraminidase (Sigma) in a buffer containing $0.05 \mathrm{M}$ sodium acetate tri-hydrate (Fisher Scientific, Whitby, ON, Canada), $1 \mathrm{~mm}$ PMSF, and $0.02 \% \mathrm{NaN}_{3}(\mathrm{pH}$ 5.5) for 1 day at $37^{\circ} \mathrm{C}$ under constant agitation. Mannose residues were degraded by mannosidase (Sigma) in a buffer containing $0.05 \mathrm{M}$ sodium acetate tri-hydrate (Fisher), $1 \mathrm{~mm}$ PMSF, and $0.02 \% \mathrm{NaN}_{3}(\mathrm{pH}$ 4.5) for 1 day at $37^{\circ} \mathrm{C}$. To neutralize the enzymatic activity, samples were boiled for $15 \mathrm{~min}$ and washed several times with $\mathrm{PBS}$ ( $\mathrm{pH}$ 7.3). Finally, samples were concentrated in Amicon Ultra $3 \mathrm{~K}$ centrifuge collector tubes (Ultracel Millipore, EMD Millipore, Etobicoke, ON, Canada).

Human colonic epithelial cells. Human colonic adenocarcinoma HT-29 cells (a gift from Dr CL Laboisse Biometadys, Faculté de Médecine, Université de Nantes, France) that constitutively express low mucin $^{20,21}$ were maintained in Dulbecco's modified Eagle's medium (12430, Gibco, LifeTechnology, Burlington, ON, Canada) with 10\% fetal bovine serum (Benchmark Gemini Bio-Products, Sacramento, CA), sodium pyruvate $(1 \mathrm{~mm})(11360$, Gibco) and penicillin $\left(100 \mathrm{U} \mathrm{ml}^{-1}\right)$ and streptomycin $\left(100 \mu \mathrm{g} \mathrm{ml}^{-1}\right.$; HyClone Thermo, Fisher Scientific, Whitby, ON, Canada) in a humidified environment of $95 \%$ air and $5 \% \mathrm{CO}_{2}$. The MUC2 H HT-29 clone (C1.16, a gift from Dr Laboisse) was obtained by long treatment with butyrate as previously described ${ }^{20}$ in which HT29 cells spontaneously and permanently differentiate into goblet cells and highly express MUC2 mucin synthesis, glycosylation, and secretion (600 times higher percentage of mucus-secreting cells than untreated HT-29 cells). ${ }^{20,50}$ The MUC2 L HT-29 clone was derived from MUC2 H cells by silencing the MUC2 gene using lentivirus shRNA technology. Specifically, short hairpin (sh) antisense targeting human MUC2 gene (NM_002457, sequencing primer $5^{\prime}$-AAACCCAGGGCTGCCTTGGAAAAG-3') composed of a 21-bp stem and a 6-bp loop (sequence $5^{\prime}$-TTGACACGTATCTTG TAGTCG-3', clone TRCN0000073552, TRC-Hs1.0 library, Open 
Biosystems, GE Healthcare, Fisher Scientific, Whitby, ON, Canada) was cloned into pLKO.1 viral vectors and cotransfected into packaging cells HEK293T along with an envelope and a packaging plasmid (Invitrogen, LifeTechnology, Burlington, ON, Canada). Viral particles containing the transfected shRNA plasmid were collected and concentrated by ultracentrifugation and titrated. To achieve maximal MUC2 silencing, the viral particles were transduced/infected in colonic MUC2 H HT-29 cells in the presence of polybrene. The transduced cells were then selected with puromycin. Using this procedure, the virus integrated into the host genome along with the MUC2 shRNA and only stable cell lines with low MUC2 expression were generated. Gene expression of MUC2, MUC5AC, and MUC5B was quantified by real-time $\mathrm{qRT}$-PCR to confirm virus integration into the host genome along with the MUC2 shRNA (Supplementary Figure S2A) as detailed below.

MUC2 H and MUC2 L HT-29 cells were grown in 24-well tissue culture plates (Corning Costar, Fisher Scientific, Whitby, ON, Canada) until $80 \%$ confluent, washed twice with PBS, and replenished with the same medium without serum. Cells were stimulated for $16 \mathrm{~h}$ with medium alone or with human IL-1 $\beta$ (Peprotech, Cedarlane, Burlington, ON, Canada), ATP disodium salt hydrate (Sigma), or sodium butyrate (Sigma). HT-29 cells similarly cultured were also stimulated with IL-1 $\beta$ (Peprotech), ATP disodium salt hydrate (Sigma), or sodium butyrate (Sigma) in the presence or absence of purified MUC2 mucin. Intracellular signaling was investigated in HT-29 cells by preincubation for 30 min with the PKC inhibitor BIM 1 (13298, Cayman Chemical, Ann Arbor, MI) before incubation with IL-1 $\beta\left(20 \mathrm{ng} \mathrm{ml}^{-1}\right)$ or ATP $(7.5 \mu \mathrm{M})$ and MUC2 for $16 \mathrm{~h}$. Cells remained viable throughout the experiments as determined by Trypan blue exclusion assay.

Colonic tissues from mice. Male, 10-12 weeks old C57BL/6 WT mice from Charles River (St Constant, QC, Canada) and $M u c 2^{-/-51}$ of the same genetic background were bred in-house and $\mathrm{F} 1 \mathrm{Muc}^{+/-}$were backcrossed to generate F2 WT $\left(\mathrm{Muc}^{+/+}\right)$, heterozygous $\left(\mathrm{Muc2}^{+/-}\right)$, and homozygous $\left(\mathrm{Muc}^{-/-}\right)$littermates. Mice were housed in sterilized, filter-top cages, maintained under specific pathogen-free conditions, and provided food and water ad libitum. Mice were fasted overnight, killed by cervical dislocation, the proximal colon was externalized aseptically, and fresh samples up to $2 \mathrm{~cm}$ in diameter were homogenized in liquid nitrogen for real-time qRT-PCR studies. Concurrently, fresh colon tissue was fixed in Carnoy's (60\% ethanol $100 \%, 30 \%$ chloroform, $10 \%$ glacial acetic acid) for $3 \mathrm{~h}$ and transferred to ethanol $100 \%$ at $4{ }^{\circ} \mathrm{C}$ and then embedded in paraffin blocks for confocal studies.

Quantification of $\beta$-defensin mRNA in human colonic cells and murine colon. Expression of $\beta$-defensin 2 and MUC2 mRNA from HT-29 cells and murine $\beta$-defensin 4 and 14 from murine colonic tissues were examined by real-time qRT-PCR. Total RNA was extracted from HT-29 cells and homogenized frozen colonic tissues by Trizol reagent (Invitrogen). Complementary DNA was prepared from $1 \mu \mathrm{g}$ of total RNA using Moloney murine leukemia virus reverse transcriptase (95048 qScript cDNA SuperMix, Quanta Biosciences, VWR International, Edmonton, $\mathrm{AB}$, Canada). RNA and DNA purity were assessed by the ratio of absorbance at 260/280 nm (NanoDrop, Thermo Scientific, Fisher Scientific, Whitby, ON, Canada) and only samples with a ratio of $\sim 1.8$ for DNA and $\sim 2.0$ for RNA were considered. Real-time qPCR was performed using a Rotor Gene 3000 real-time PCR system (Corbett Research, Qiagen, Toronto, ON, Canada). Each reaction mixture contained $100 \mathrm{ng}$ of complementary DNA $(10 \mu \mathrm{l}), 2 \times$ Rotor-Gene SYBR Green PCR Master Mix (Qiagen, Toronto, ON, Canada; $12.5 \mu \mathrm{l})$, and $1 \mu \mathrm{M}$ of primers $(2.5 \mu \mathrm{l})$. The primer sequences for the following genes were used. For human MUC2 (sense 5'-CAGCACCGATTGCTGAGTTG-3' ${ }^{\prime}$, reverse 5' -GCTGGTC ATCTCAA-TGGCAG- $3^{\prime}$ ); MUC5AC (sense $5^{\prime}$-GCATCCAGCTCTG TGGCTTA- $3^{\prime}$, antisense $5^{\prime}$-CAC-TGTCAACCCCTCTGACC-3'); MUC5B (sense $5^{\prime}$-TGCAATCAGCACTGTGACATTGAC-3', anti- sense $5^{\prime}$-TTCTCCAGGGTCCAGGTCTCATTC-3'); hBD-2 (DEFB4A NM_004942.2, PPH11010A, RT ${ }^{2}$ qPCR Primer Assay, Qiagen) and glyceraldehyde-3-phosphate dehydrogenase (GAPDH) (sense, 5' -TGCA CCACCAACTGCTTAGC-3'; antisense, 5' -GGCATGGACTGTGGTC ATGAG-3'). For mouse: murine $\beta$-defensin 4 (Defb4 NM_019728.4, PPM29171A, RT ${ }^{2}$ qPCR Primer Assay, Qiagen), murine $\beta$-defensin 14 (Defb14 NM_183026.2, PPM41918A, RT ${ }^{2}$ qPCR Primer Assay, Qiagen), and murine actin (sense, 5'-CTACAATGAGCTGCGTGTG-3'; antisense, $5^{\prime}$-TGGGGTGTTGAAGGTCTC- $3^{\prime}$ ). The reaction mixtures were incubated for $95^{\circ} \mathrm{C}$ for $5 \mathrm{~min}$, followed by denaturation for $5 \mathrm{~s}$ at $95^{\circ} \mathrm{C}$ and combined annealing/extension for $10 \mathrm{~s}$ at $60^{\circ} \mathrm{C}$ for a total of 40 cycles. Values of target mRNA were corrected relative to the housekeeping gene coding for human GAPDH or murine actin. Data were analyzed using the $2^{-\Delta \Delta \mathrm{CT}}$ methods and expressed as fold changes (mean \pm s.e.).

Confocal immunofluorescence microscopy of human colonic cells and murine colon. Murine colonic tissues fixed in Carnoy's were sectioned $(7 \mu \mathrm{m})$ and deparaffinized by xylene substitute (Neo-Clear, Millipore), followed by decreasing concentrations of ethanol and running tap water. Slides were boiled in $10 \mathrm{~mm}$ sodium citrate (Sigma) plus $0.05 \%$ Tween-20 (pH 6) for $20 \mathrm{~min}$ in microwave oven for antigen retrieval and then cooled at room temperature (RT) and rinsed in PBS. Free aldehydes were blocked by $0.1 \mathrm{~m}$ glycine in PBS for $10 \mathrm{~min}$ at RT. Human HT-29 cells grown in 12-well plate were rinsed with PBS and fixed in $4 \%$ paraformaldehyde with $150 \mathrm{~mm} \mathrm{NaCl}, 4 \mathrm{~mm} \mathrm{NaH}_{2} \mathrm{PO}_{4}$, and $5 \mathrm{~mm} \mathrm{KCL}$ ( $\mathrm{pH} 7.4$ ) for $10 \mathrm{~min}$ at RT. Murine and human sections were rinsed in cold PBS plus Tween $0.05 \%$ ( $\mathrm{pH}$ 7.2) (PBS-Tw), permeabilized with PBS-Tw plus $0.25 \%$ Triton X-100 for 10 min at RT, and rinsed in cold PBS-Tw. Preparations from murine colon and human HT-29 cells were blocked with PBS-Tw, 1\% bovine serum albumin, $10 \%$ goat serum, $0.3 \mathrm{M}$ glycine, and $0.05 \%$ saponin for $2 \mathrm{~h}$ at RT and rinsed with PBS-Tw. Murine tissue was blotted with affinitypurified rabbit IgG anti-hBD-2 (Abcam, Cambridge, MA) or with affinity-purified rabbit IgG anti-LS 174T MUC2 antibodies. ${ }^{31}$ Human HT-29 cells were blotted with affinity-purified rabbit IgG anti-hBD-2 (Abcam) and affinity-purified goat IgG anti-human MUC2 (Santa Cruz) antibodies. Sections were rinsed with cold PBS-Tw. As secondary antibodies, human cells were blotted with DyLight 647-affinity pure donkey anti-rabbit IgG F(ab')2 fragment-specific antibodies and DyLight 594-affinity pure donkey anti-goat IgG F(ab')2 fragmentspecific antibodies, and murine tissues with DyLight 647-affinity pure donkey anti-rabbit IgG $\mathrm{F}(\mathrm{ab}$ ')2 fragment-specific antibodies. Secondary antibodies were diluted 1:1,000 in PBS-Tw plus $1 \%$ bovine serum albumin and incubated for $1 \mathrm{~h}$ at RT. Preparations were rinsed in cold PBS-Tw and nuclei were counterstained with 4',6-diamidino-2phenylindole. Sections were rinsed with cold PBS-Tw and mounted with FluorSave reagent (Calbiochem, EMB Millipore, Etobicoke, ON, Canada). Slides were examined using a FluoView FV1000 confocal immunofluorescence microscope (Olympus, Toronto, ON, Canada).

Determination of secreted human $\beta$-defensin in human epithelial colonic cells. Secreted hBD-2 peptides were quantified in the supernatant of cultured cells by ELISA as per the manufacturer's specifications (Peprotech, Cedarlane, Burlington, ON, Canada). Briefly, 96-well ELISA plates were coated with $100 \mu$ l of capture antibody diluted at $0.5 \mu \mathrm{g} \mathrm{ml}^{-1}$ overnight at RT and blocked with $1 \%$ bovine serum albumin in PBS for $2 \mathrm{~h}$ at RT. Plates were incubated in quadruplicate with $100 \mu \mathrm{l}$ of supernatant of cultured cells for $2 \mathrm{~h}$ at RT and then with $100 \mu \mathrm{l}$ of detection antibody diluted at $0.5 \mu \mathrm{g} \mathrm{ml}^{-1}$ for $2 \mathrm{~h}$ at RT. After incubation with $100 \mu \mathrm{l}$ of avidin peroxidase diluted 1:2,000 for $30 \mathrm{~min}$ at RT, the color was developed by incubating plates with $100 \mu \mathrm{l}$ of $3,3^{\prime}, 5,5^{\prime}$-tetramethylbenzidine (Sigma) for $15 \mathrm{~min}$ at RT and substrate stopped by the addition of $50 \mu \mathrm{l}$ of $2 \mathrm{M} \mathrm{H}_{2} \mathrm{SO}_{4}$. Absorbance was read at 450/550 $\lambda$ on an ELISA microplate reader (Bio-Rad Laboratories, Hercules, CA). Several washes with PBS-Tw were done after each step. 
An ELISA kit was modified to detect binding of hBD-2 peptides to mucin. ELISA plates were coated with different concentrations of purified MUC2 mucin diluted in $100 \mu \mathrm{l}$ of coating buffer $\left(50 \mathrm{~mm} \mathrm{NaHCO}_{3} /\right.$ $\mathrm{Na}_{2} \mathrm{CO}_{3}, \mathrm{pH} 9.6$ ) in 96 wells overnight at $4{ }^{\circ} \mathrm{C}$, washed, and then incubated with $200 \mathrm{pg}$ of rhBD-2 for $2 \mathrm{~h}$. The supernatant (i.e., containing unbound hBD-2 peptides) was collected and immediately processed for detection of hBD-2 peptides as described above. That MUC2 effectively attached to the wells was verified in previous studies in which only $10 \%$ of the added MUC2 was recovered after incubation overnight at $4{ }^{\circ} \mathrm{C}$. For all ELISAs, a standard curve comprised recombinant hBD-2 (Peprotech) and doubling dilutions from 1 to $200 \mathrm{pg} \mathrm{ml}^{-1}$ was included to calculate the hBD-2 peptide concentration in the samples.

Bacterial cultures. Nonpathogenic K-12 derivate HB101 E. and enteropathogenic O127:H6 (E2348/69 EPEC) were cultured in LB agar. B. vulgatus (ATCC 8482) and Clostridium difficile (R20291) were cultured in anaerobiosis into fastidious anaerobe agar (Lab090, LabM, Lancashire, UK).

Antimicrobial activity of $\beta$-defensins. Fresh E. coli colonies were grown in tryptic soy broth (2209 Fluka, Sigma) in aerobiosis for $2 \mathrm{~h}$ at $37^{\circ} \mathrm{C}$ with vigorous shaking (300 r.p.m.). Colonies of $B$. vulgatus and $C$. difficile were grown in brain hearth infusion (BD Canada, Mississauga, ON, Canada, Difco) in anaerobiosis for $48 \mathrm{~h}$ at $37^{\circ} \mathrm{C}$. For the antimicrobial test, $E$ coli was diluted by $\mathrm{A}^{\circ} 600$ spectrophotometry to a final concentration of $1 \times 10^{5}$ colony-forming units per $\mathrm{ml}$ in a MT-LB buffer containing $50 \mathrm{~mm} \mathrm{NaHCO}_{3}$ (Sigma), $16 \mathrm{~mm}$ disodium hydrogen phosphate, $5 \mathrm{~mm}$ sodium dihydrogen phosphate, plus $1 \% \mathrm{LB}$ broth. ${ }^{28}$ B. vulgatus and C. difficile were diluted to $60 \times 10^{4}$ colonyforming units in the same buffer medium but with $18 \%$ brain hearth infusion broth. ${ }^{435}$ The bacterial suspensions were incubated with recombinant hBD-2 (Peprotech) alone or coincubated with MUC2 mucin or type III mucin from porcine stomach (Sigma M1778) for $2 \mathrm{~h}$ at $37^{\circ} \mathrm{C}$ with constant agitation. Surviving colony-forming units were quantified by incubating the bacterial suspension $(8 \mu \mathrm{l})$ with CellTiterGlo Luminescent Cell Viability assay substrate (Promega, Madison, MI) $(35 \mu \mathrm{l})$ in white solid 96-well plates (Greiner Bio-One, Monroe, NC) and luminescence measured in a luminometer (Victor2, Wallac 1420 3.0, PerkinElmer, Guelph, ON, Canada). The number of bacteria was calculated by a standard curve with known number of bacteria and checked by counting colonies in dilutions plated directly onto LB agar or fastidious anaerobe agar after incubation for 1 to 2 days at $37^{\circ} \mathrm{C}$.

Murine mucin secretion in in vivo studies. To quantify an in vivo role for colonic mucin in protecting bacteria against $\beta$-defensin, fresh colonic contents were obtained from $\mathrm{Muc2}^{+/+}, \mathrm{Muc2}^{+/-}$, and $M u c 2^{-/}$littermates. Mice were fasted overnight and killed and the colon was excised and opened longitudinally. Colonic mucosal secretions were obtained by gently scraping and flushing with PBS. Samples were vortexed and centrifuged $\left(1,000 \mathrm{~g}, 10 \mathrm{~min}, 4^{\circ} \mathrm{C}\right)$ to remove cellular debris and immediately frozen at $-70{ }^{\circ} \mathrm{C}$. Surviving EPEC after incubation with murine colonic contents (total $20 \mu \mathrm{g}$ protein) was calculated by CellTiter-Glo Luminescent Cell Viability assay (Promega) as described above.

Scanning electron microscopy. EPEC $\left(10^{6}\right.$ per ml $)$ incubated with MT-LB buffer only or in combination with hBD-2 $(2 \mu \mathrm{M})$ and/or MUC2 mucin $\left(20 \mu \mathrm{g} \mathrm{ml}^{-1}\right)$ for $2 \mathrm{~h}$ were rinsed and spin at 4,000 $\mathrm{g}$ with PBS. Bacteria were fixed with $2.5 \%$ in $0.2 \mathrm{M}$ cacodylate buffer for $45 \mathrm{~min}$ at $4{ }^{\circ} \mathrm{C}$ and washed three times with $0.2 \mathrm{M}$ cacodylate buffer. Bacteria were dehydrated through ethanol gradient $(30,50,70,80,90,95,100$, $100 \%)$ and the critical-point dry achieved by increasing gradient with hexamethyldisilazane (HMDS) (100\% ethanol; 2:1 ethanol: HMDS; 1:2 ethanol: HMDS and 100\% HMDS). Bacteria were sputter coated with gold palladium and imaged using a FEI XL30 scanning electron microscope. Profiles showing membrane damage and shortening was estimated by examining 100 bacteria/condition in microscopic fields randomly chosen through observation and statistically analyzed by nonparametric $\chi^{2}$ tests.
Statistical analysis. Differences between groups were analyzed by unpaired $t$-test or analysis of variance and Tukey's post-tests (GraphPad Prism 5.0 Mac, GraphPad Software Inc, La Jolla, CA). Graphs represent two to three independent experiments, and error bars represent means \pm s.e. Differences in values were considered significant when $P$ was $<0.05$.

SUPPLEMENTARY MATERIAL is linked to the online version of the paper at http://www.nature.com/mi

\section{ACKNOWLEDGMENTS}

We thank Michael Schoel from the Microscopy and Imaging facility at University of Calgary for his assistance in the SEM studies. This work was supported by a grant from the Canadian Institute of Health Research (CIHR) to K.C. E.R.C. was supported by an Alberta Innovates-Health Solutions Fellowship Award. The Live Cell Imaging Facility is funded by an equipment and infrastructure grant from the Canadian Foundation Innovation (CFI) and the Alberta Science and Research Authority.

\section{AUTHOR CONTRIBUTIONS}

E.R.C. and K.C. conceived, designed, and performed the experiments and analyzed the data. V.K.-S. performed the animal experiments. F.M. performed mucin isolation and purification. E.R.C. and K.C. wrote the manuscript.

\section{DISCLOSURE}

The authors declared no conflict of interest.

c 2015 Society for Mucosal Immunology

\section{REFERENCES}

1. Johansson, M.E. etal. The inner of the two Muc2 mucin-dependent mucus layers in colon is devoid of bacteria. Proc. Natl. Acad. Sci. USA 105, 15064-15069 (2008).

2. Ganz, T. Defensins: antimicrobial peptides of innate immunity. Nat. Rev. Immunol. 3, 710-720 (2003).

3. Harder, J., Bartels, J., Christophers, E. \& Schroder, J.M. A peptide antibiotic from human skin. Nature 387, 861 (1997).

4. Yang, D. et al. Beta-defensins: linking innate and adaptive immunity through dendritic and T cell CCR6. Science 286, 525-528 (1999).

5. O'Neil, D.A. et al. Expression and regulation of the human beta-defensins hBD-1 and hBD-2 in intestinal epithelium. J. Immunol. 163, 6718-6724 (1999).

6. Vora, P. et al. Beta-defensin-2 expression is regulated by TLR signaling in intestinal epithelial cells. J. Immunol. 173, 5398-5405 (2004).

7. Backhed, F., Ley, R.E., Sonnenburg, J.L., Peterson, D.A. \& Gordon, J.I. Host-bacterial mutualism in the human intestine. Science 307, 1915-1920 (2005).

8. Fahlgren, A., Hammarstrom, S., Danielsson, A. \& Hammarstrom, M.L. beta-Defensin-3 and -4 in intestinal epithelial cells display increased mRNA expression in ulcerative colitis. Clin. Exp. Immunol. 137, 379-385 (2004).

9. Wehkamp, J. et al. Inducible and constitutive beta-defensins are differentially expressed in Crohn's disease and ulcerative colitis. Inflamm. Bowel Dis. 9, 215-223 (2003).

10. Pullan, R.D. et al. Thickness of adherent mucus gel on colonic mucosa in humans and its relevance to colitis. Gut 35, 353-359 (1994).

11. McCormick, D.A., Horton, L.W. \& Mee, A.S. Mucin depletion in inflammatory bowel disease. J. Clin. Pathol. 43, 143-146 (1990).

12. Gersemann, M. et al. Differences in goblet cell differentiation between Crohn's disease and ulcerative colitis. Differentiation 77, 84-94 (2009).

13. Manichanh, C., Borruel, N., Casellas, F. \& Guarner, F. The gut microbiota in IBD. Nat. Rev. Gastroenterol. Hepatol. 9, 599-608 (2012).

14. Chen, G.Y. \& Nunez, G. Inflammasomes in intestinal inflammation and cancer. Gastroenterology 141, 1986-1999 (2011). 
15. Ivison, S.M. et al. The stress signal extracellular ATP modulates antiflagellin immune responses in intestinal epithelial cells. Inflamm. Bowel Dis. 17, 319-333 (2011).

16. Kusu, T. et al. Ecto-nucleoside triphosphate diphosphohydrolase 7 controls Th17 cell responses through regulation of luminal ATP in the small intestine. J. Immunol. 190, 774-783 (2013).

17. Atarashi, K. et al. ATP drives lamina propria $T(H) 17$ cell differentiation. Nature 455, 808-812 (2008).

18. Scheppach, W. Effects of short chain fatty acids on gut morphology and function. Gut 35, S35-S38 (1994).

19. El Aidy, S., Van den Abbeele, P., Van de Wiele, T., Louis, P. \& Kleerebezem, M. Intestinal colonization: how key microbial players become established in this dynamic process: microbial metabolic activities and the interplay between the host and microbes. BioEssays 35, 913-923 (2013).

20. Augeron, C. \& Laboisse, C.L. Emergence of permanently differentiated cell clones in a human colonic cancer cell line in culture after treatment with sodium butyrate. Cancer Res. 44, 3961-3969 (1984).

21. Bu, X.D., Li, N., Tian, X.Q. \& Huang, P.L. Caco-2 and LS174T cell lines provide different models for studying mucin expression in colon cancer. Tissue Cell 43, 201-206 (2011).

22. Schwab, M. et al. The dietary histone deacetylase inhibitor sulforaphane induces human beta-defensin-2 in intestinal epithelial cells. Immunology 125, 241-251 (2008).

23. Pazgier, M., Hoover, D.M., Yang, D., Lu, W. \& Lubkowski, J. Human betadefensins. Cell. Mol. Life Sci. 63, 1294-1313 (2006).

24. Hartmann, M. et al. Damage of the bacterial cell envelope by antimicrobial peptides gramicidin S and PGLa as revealed by transmission and scanning electron microscopy. Antimicrob. Agents Chemother. 54, 3132-3142 (2010).

25. Johansson, M.E., Larsson, J.M. \& Hansson, G.C. The two mucus layers of colon are organized by the MUC2 mucin, whereas the outer layer is a legislator of host-microbial interactions. Proc. Natl. Acad. Sci. USA 108 , 4659-4665 (2011).

26. Sajjan, S.U. \& Forstner, J.F. Characteristics of binding of Escherichia coli serotype O157:H7 strain CL-49 to purified intestinal mucin. Infect. Immun. 58, 860-867 (1990).

27. Sajjan, S.U. \& Forstner, J.F. Role of the putative "link" glycopeptide of intestinal mucin in binding of piliated Escherichia coli serotype O157:H7 strain CL-49. Infect. Immun. 58, 868-873 (1990).

28. Rohrl, J., Yang, D., Oppenheim, J.J. \& Hehlgans, T. Specific binding and chemotactic activity of mBD4 and its functional orthologue hBD2 to CCR6expressing cells. J. Biol. Chem. 285, 7028-7034 (2010).

29. Jia, H.P. et al. A novel murine beta -defensin expressed in tongue, esophagus, and trachea. J. Biol. Chem. 275, 33314-33320 (2000).

30. Rohrl, J., Yang, D., Oppenheim, J.J. \& Hehlgans, T. Identification and biological characterization of mouse beta-defensin 14 , the orthologue of human beta-defensin 3. J. Biol. Chem. 283, 5414-5419 (2008).

31. Belley, A., Keller, K., Grove, J. \& Chadee, K. Interaction of LS174T human colon cancer cell mucins with Entamoeba histolytica: an in vitro model for colonic disease. Gastroenterology 111, 1484-1492 (1996).

32. Witthoft, T. et al. Enhanced human beta-defensin-2 (hBD-2) expression by corticosteroids is independent of NF-kappaB in colonic epithelial cells (CaCo2). Dig. Dis. Sci. 50, 1252-1259 (2005).

33. Place, R.F., Noonan, E.J. \& Giardina, C. HDAC inhibition prevents NFkappa B activation by suppressing proteasome activity: down-regulation of proteasome subunit expression stabilizes I kappa B alpha. Biochem. Pharmacol. 70, 394-406 (2005).

34. Jang, B.C. et al. Up-regulation of human beta-defensin 2 by interleukin1 beta in A549 cells: involvement of PI3K, PKC, p38 MAPK, JNK, and NFkappaB. Biochem. Biophys. Res. Commun. 320, 1026-1033 (2004).

35. Tsutsumi-Ishii, Y. \& Nagaoka, I. NF-kappa B-mediated transcriptional regulation of human beta-defensin-2 gene following lipopolysaccharide stimulation. J. Leukoc. Biol. 71, 154-162 (2002).
36. Mendez-Samperio, P., Miranda, E. \& Trejo, A. Regulation of human betadefensin- 2 by Mycobacterium bovis bacillus Calmette-Guerin (BCG): involvement of PKC, JNK, and PI3K in human lung epithelial cell line (A549). Peptides 29, 1657-1663 (2008).

37. Hirota, S.A. et al. NLRP3 inflammasome plays a key role in the regulation of intestinal homeostasis. Inflamm. Bowel Dis. 17, 1359-1372 (2011).

38. Bergstrom, K.S. et al. Muc2 protects against lethal infectious colitis by disassociating pathogenic and commensal bacteria from the colonic mucosa. PLoS Pathog. 6, e1000902 (2010).

39. Burger-van Paassen, N. et al. Mucin Muc2 deficiency and weaning influences the expression of the innate defense genes Reg3beta, Reg3gamma and angiogenin-4. PLoS One 7, e38798 (2012).

40. Ott, S.J. et al. Reduction in diversity of the colonic mucosa associated bacterial microflora in patients with active inflammatory bowel disease. Gut 53, 685-693 (2004).

41. Nguyen, G.C., Kaplan, G.G., Harris, M.L. \& Brant, S.R. A national survey of the prevalence and impact of Clostridium difficile infection among hospitalized inflammatory bowel disease patients. Am. J. Gastroenterol. 103, 1443-1450 (2008).

42. Rodemann, J.F., Dubberke, E.R., Reske, K.A., Seo da, H. \& Stone, C.D. Incidence of Clostridium difficile infection in inflammatory bowel disease. Clin. Gastroenterol. Hepatol. 5, 339-344 (2007).

43. Nuding, S. et al. Antibacterial activity of human defensins on anaerobic intestinal bacterial species: a major role of HBD-3. Microbes Infect. 11, 384-393 (2009).

44. Lee, H.Y. et al. Antimicrobial activity of innate immune molecules against Streptococcus pneumoniae, Moraxella catarrhalis and nontypeable Haemophilus influenzae. BMC Infect. Dis. 4, 12 (2004).

45. Antoni, L. et al. Human colonic mucus is a reservoir for antimicrobial peptides. J. Crohns Colitis 7, 652-664 (2013).

46. Tai, E.K. et al. Intrarectal administration of mCRAMP-encoding plasmid reverses exacerbated colitis in Cnlp(-/-) mice. Gene Therapy 20, 187-193 (2013).

47. Hollingsworth, M.A., Strawhecker, J.M., Caffrey, T.C. \& Mack, D.R. Expression of MUC1, MUC2, MUC3 and MUC4 mucin mRNAs in human pancreatic and intestinal tumor cell lines. Int. J. Cancer 57, 198-203 (1994).

48. Atuma, C., Strugala, V., Allen, A. \& Holm, L. The adherent gastrointestinal mucus gel layer: thickness and physical state in vivo. Am. J. Physiol. Gastrointest. Liver Physiol. 280, G922-G929 (2001).

49. Chadee, K., Petri, W.A. Jr., Innes, D.J. \& Ravdin, J.I. Rat and human colonic mucins bind to and inhibit adherence lectin of Entamoeba histolytica. J. Clin. Invest. 80, 1245-1254 (1987).

50. Augenlicht, L., Shi, L., Mariadason, J., Laboisse, C. \& Velcich, A. Repression of MUC2 gene expression by butyrate, a physiological regulator of intestinal cell maturation. Oncogene 22, 4983-4992 (2003).

51. Velcich, A. et al. Colorectal cancer in mice genetically deficient in the mucin Muc2. Science 295, 1726-1729 (2002).

52. Dorschner, R.A. et al. The mammalian ionic environment dictates microbial susceptibility to antimicrobial defense peptides. FASEB J 20, 35-42 (2006).

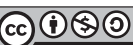

This work is licensed under a Creative Commons Attribution-NonCommercial-ShareAlike $\quad 4.0$

International License. The images or other third party material in this article are included in the article's Creative Commons license, unlessindicated otherwisein thecreditline; if thematerial is not included under the Creative Commons license, users will need to obtain permission from the license holder to reproduce the material. To view a copy of this license, visit http:// creativecommons.org/licenses/by-nc-sa/4.0/ 